\title{
Influence of thermomechanical processing on the grain size, texture and mechanical properties of $\mathrm{Mg}$-Al alloys
}

\author{
B. Srinivasarao ${ }^{1}$, J.A. del Valle ${ }^{2}$, O.A. Ruano ${ }^{2}$, M.T. Pérez-Prado ${ }^{1}$ \\ 1Madrid Institute for Advanced Studies of Materials (IMDEA-Materials Institute) \\ C/ Profesor Aranguren s/n, 28040 - Madrid, Spain \\ 2Department of Physical Metallurgy, Centro Nacional de Investigaciones Metalúrgicas \\ (CENIM), CSIC, Avenida de Gregorio del Amo 8, Madrid 28040, Spain
}

\begin{abstract}
The work carried out by the authors over the last decade on the processing, microstructural characterization and the mechanical behaviour of $\mathrm{Mg}$ alloys is reviewed. In particular, the potential for grain refinement and for the development of specific textures of large strain hot rolling (LSHR), equal channel angular pressing (ECAP) and accumulative roll bonding (ARB) is discussed. The recrystallization and the deformation mechanisms predominant in $\mathrm{Mg}$ alloys are analyzed as a function of the grain size and the texture in a wide range of stresses, strain rates and temperatures. Finally, the the feasibility of superplatic forming of Mg alloys was examined, taking into account the influence of factors such as grain size stability and microstructural heterogeneities.
\end{abstract}

Keywords: Magnesium alloys, Processing, Recrystallization, Texture, Hot working, Superplasticity, Grain refinement

\section{Introduction}

The XXI century has been marked by an increasing awareness of the need to limit consumption of the already scarce fossil fuel resources and to preserve the environment. These issues constitute a tremendous driving force to achieve weight savings in the automotive and aerospace industries. Magnesium alloys have thus received great attention over the last decade due to their low density and high specific strength compared to steel and aluminium [1].

These materials have, however, a number of disadvantages, such as low absolute values of strength, uniform elongation, tensile reduction of area, sheet forming limits, cold rollability and bendability [2]. This is attributed to an insufficient number of slip and twinning systems (VonMises criterion). At room temperature magnesium deforms by basal slip (two independent slip systems) and mechanical twinning. The other slip modes are difficult to activate because of the larger critical resolved shear stresses ( $\tau$ non-basal). According to early studies on single crystals $[3,4]$ the ratio of $\tau_{\text {non-basal }} / \tau_{\text {basal }}$ is approximately 100 . Modeling works have also given a wide range of values for this ratio. For example, the mechanical behavior of alloy AZ31 has been modeled successfully using the following ratios: $\tau_{\text {prism }} / \tau_{\text {basal }}=3.5[5], \tau_{\text {prism }} / \tau_{\text {basal }}=5.5$ [6], prism $/ \tau$ basal $=3-7$ [7], $\tau_{\text {prism }} / \tau_{\text {basal }}=30$ [8], $\tau_{\text {prism }} / \tau_{\text {basal }}=27.5$ [9]. In all cases, non-basal modes are significantly "harder" than basal slip.

There have recently been numerous efforts to improve the mechanical behavior of $\mathrm{Mg}$ alloys. One path consists on acting on the ratio $\tau$ non-basal/ $\tau$ basal. The $\tau$ non-basal can be lowered by the addition of solute elements such as Li and Ce etc. [10-13], which reduce the c/a value or increase the stacking fault energy. A second path consists on reducing the grain size by 
thermomechanical processing $[14,15]$. This results in an increase of the room temperature yield strength (Hall-Petch) and on the formability at warm/high temperatures due to the enhancement of the grain boundary sliding mechanism. At such warm/high temperatures, it is possible to produce an increase in the strain rate sensitivity parameter to values close to 0.5 . The increase in sensitivity has the mechanical effect of generating large tensile deformations; this well known phenomenon is termed superplasticity. Enhanced superplastic elongations are indeed observed in $\mathrm{Mg}$ alloys for grain sizes as high as 20 microns. Moreover, this change in deformation mechanism results in a mechanical behavior that no longer depends on the relative values of tnon-basal and $\tau$ basal, which gives the additional benefit that the material becomes more isotropic; i.e., the mechanical behavior is much less dependent of texture [16].

Several processing methods are used to modify the grain size as well as texture of $\mathrm{Mg}$ alloys [17-27]. Conventional thermo-mechanical ingot processing, particularly by hot extrusion, has allowed preparing microstructures with grain sizes finer than $10 \mu \mathrm{m}$. In recent years methods for grain refinement through severe plastic deformation (SPD) have been widely embraced by the scientific community $[19,20]$. These methods include equal channel angular extrusion (ECAE), high pressure torsion (HPT), accumulative roll bonding (ARB), friction stir processing (FSP), and others. The SPD techniques allow engineering of microstructures with submicron grain sizes [20]. Decreasing the grain size to few microns results in an increase in yield stress according to the Hall-Petch relation but also in a decrease in the work hardening rate $[21,22]$ with a consequent decrease in elongation from $15 \%$ to $10 \%$ in the AZ31 alloy, for example. Simultaneously, a noticeable increase in both the strain rate sensitivity and the normal plastic anisotropy was reported [21, 23, 24]. The strong correlation between normal anisotropy and the amount of prismatic slip gives evidence of a change in the slip system activity, i.e., an increased non-basal slip activity [24-26].

Some more expensive techniques, such as powder metallurgy, allow fabricating magnesium based materials with submicron or even nanometric grain sizes. For example, Hwang et al. [27] have prepared compression samples of pure $\mathrm{Mg}$ with grain sizes close to 45 $\mathrm{nm}$ by processing powders of conventional grain size by high energy milling and cold compaction [27]. They report an increase of the strain rate sensitivity at room temperature up to values consistent with the occurrence of grain boundary sliding. Choi et al. [28] have reported that, as grain size decreases in $\mathrm{Mg}$ alloys to the nanocrystalline scale, the twin activity decreases, the yield stress deviates from the Hall-Petch behavior, the work hardening decreases and the strain rate sensitivity increases. However, they state that the strain rate sensitivity is still much below the value for conventional grain boundary sliding $(\mathrm{m}=0.5)$. Although the deformation mechanisms for nanocrystalline materials are currently not fully elucidated, all studies show an increased strain rate sensitivity, which compensates the negative effect of the decrease in strain hardening, resulting in an increase in ductility [29, 30].

A third way to improve the mechanical behaviour of $\mathrm{Mg}$ alloys consists on modifying the texture, which has an important influence on the ductility and on the plastic anisotropy [31-42]. Depending on the processing route followed, different types of textures are obtained. For example, a random texture results from casting and a basal fiber texture develops after hot rolling [31-33]. During extrusion, the c-axes align perpendicular to the extrusion direction. Considerable efforts have been devoted to develop novel textures by innovative processing techniques such as asymmetric rolling [40-42]. If a tensile test is carried out in a rolled $\mathrm{Mg}$ sheet along the basal fiber axis, basal slip becomes difficult and non-basal deformation modes become active. However, if the tensile axis is inclined $45^{\circ}$ to the basal fiber axis, basal slip takes place massively and ductility increases $[21,34,35]$. Tensile curves show a work hardening stage II, of constant hardening rate during a strain interval of 0.1-0.2. This is characteristic of materials deforming with one or two active slip systems. Therefore the parabolic stage III, characterized by a linear decrease of the work hardening rate which leads to neck formation, is delayed to higher strains in comparison to rolled samples with a basal texture [21]. The texture can be additionally modified by composition changes, such as by the addition of rare earth elements ( $\mathrm{La}, \mathrm{Ce}, \mathrm{Gd}, \mathrm{Nd})[36-39,43]$. The reasons why, for example, random textures can be obtained 
after processing a Mg-RE alloy by hot extrusion are still not well known.

The present paper provides a review of the work carried out by the authors within this context during the last decade. Several Mg-Al alloys were processed by equal channel angular extrusion (ECAE or ECAP), large strain hot rolling (LSHR), accumulative roll bonding (ARB) and annealing with the aim of decreasing grain size and improving the mechanical behaviour. Room temperature and high temperature properties were studied and correlated with the microstructure. The results of our investigations are compared to those of other authors and discussed in the frame of the current understanding on $\mathrm{Mg}$ alloys.

\section{Effect of processing on grain size and texture}

The processing routes contemplated in this review are performed under hot working conditions. Hot working is defined as the application of deformation under the conditions of temperature and strain rate such that recovery and recrystallization processes take place simultaneously with the deformation [44]. Recovery and recrystallization processes in magnesium and its alloys are dependent on several factors such as temperature $[45,46]$, strain rate [47], the operative deformation mechanism [48-52], texture [53-55], etc. Several studies were performed to understand the influence of each of these factors by compression or torsion tests [46, 48-51, 56, 57]. In general, dynamic recrystallization (DRX) may occur in one of two ways: discontinuously (DDRX) involving the formation of dislocation-free nuclei, separated from the deformed matrix by high angle boundaries and subsequent growth of these nuclei, and continuously (CDRX) involving the formation of cell walls and subgrain boundaries during the first stages of deformation as a consequence of the interaction of dislocations gliding in different slip systems. As strain progresses, subboundary misorientation increases by dislocation accumulation and, simultaneously, increasingly better defined interfaces develop. This process leads ultimately to the formation of high angle boundaries [57, 58].

In the case of magnesium, Ion et al. [46] proposed a special type of DRX, termed rotational dynamic recrystallization ( $\mathrm{RDRX}$ ), consisting of a succession of lattice rotations (kinking) at grain boundaries, leading to the formation of subgrains and finally recrystallized grains with high angle boundaries. Moreover, Humphreys et al. [46, 57] claim that during this process little boundary migration occurs and no clear division between nucleation and growth can be established. Therefore, this mechanism is included inside the group of CDRX mechanisms. It is considered that RDRX is responsible for the formation of shear bands during large strain hot rolling [15].

In the last decade there has been a considerable debate about the operation of CDRX or DDRX. The predominance of these DRX mechanisms appears to depend on temperature and on the deformation conditions. Humphreys and co-workers [46, 57] recognized that DDRX is favored over RDRX at temperatures higher than about $600 \mathrm{~K}$. The use of the EBSD technique has provided new evidence of RDRX at deformation temperatures below $523 \mathrm{~K}$, and low strain rates, [59] and at temperatures as high as $673 \mathrm{~K}$ at very high strain rates 103 [60]. Summarizing, DDRX is expected in the case of low Zener-Hollomon parameter, $Z=$ sewp (Q/RT) while for large values of Z, CDRX or RDRX could take place.

Galiyev et al. [56] and Sitdikov and Kaibyshev [51] made an effort to correlate the mode of dislocation movement (cross-slip vs. climb) with the DRX mechanism in a ZK60 Mg-alloy. The main conclusion of their work is that CDRX is linked to deformation controlled by crossslip while DDRX is related to deformation controlled by climb. For temperatures below $473 \mathrm{~K} \mathrm{a}$ DRX mechanism inspired in RDRX was proposed. The DRX mechanisms of the AZ31 alloy were analyzed by McQueen and co-workers from 453 to $723 \mathrm{~K}$ [45, 61]. In this case a climb process, with an activation energy close to that for self diffusion, Qself, was found to control creep in the whole range of temperatures. McQueen and co-workers agree with Humphreys et al. $[46,57]$ in the role of the grain mantle to produce rotated subgrains creating high angle boundaries, but propose that this is a base for successive boundary migration [45] and thus claim 
that recrystallization takes place by DDRX.

Distinguishing between DDRX and CDRX in certain $\mathrm{Z}$ ranges is complex. On the one hand, optical microscopy has revealed the formation of bulges in grain boundaries during hot deformation, which has been interpreted as a sign of conventional DDRX [57]. Bulging of grain boundaries is often observed in magnesium alloys and considered as a nucleation mechanism of new grains, i.e. as a prelude of DDRX, leading to a "necklace" of dynamically recrystallized grains on the pre-existing grain boundaries. Grain boundary bulging is usually assumed to be related to strain-induced grain boundary migration. Studies on the dependence of the recrystallization and flow stress with the initial grain size, add evidence in favor of DDRX at temperatures in the range 573-723 $\mathrm{K}[50,62]$. On the other hand, TEM and EBSD-based investigations observed the conversion of dislocation cell walls into subgrain boundaries [45] and, ultimately, into high angle boundaries $[51,56,63,64]$ in the same temperature range (573723K). Moreover, Sitdikov et al. [51] and Yang et al. [13] explain that the bulging process in magnesium involves the formation of low-angle sub-boundaries, which cut off the bulge protrusion from the grain body, the misorientation of such boundaries gradually increases leading to the development of a high angle boundary. This means that, to some extent, DDRX in magnesium partially involves a continuous DRX component.

The influence of the operative slip system on the DRX of the AZ31 alloy has been profusely investigated [48-50, 55, 62]. These studies deal in most cases with deformation in the DDRX regime, and include compression/tensile tests of samples with different textures, or with a well-defined texture but different specimen orientations. Barnett et al. [48] found that the progress of recrystallization was sensitive to changes in the orientation of the compression axis. They observed that the lowest recrystallized volume fraction corresponded to a "c-axis constraint" orientation that is mechanically similar to testing a rolled sample in tension along the rolling direction because in both cases prismatic slip is favored. Barnett et al. [48] attribute this behavior to the predominance of prismatic slip favored in detriment of twinning [48, 49]. Myshlyaev et al. [45] also emphasized the role of the microstructure heterogeneities, arising from twinning and multiple slip, on inducing DRX nuclei. In case of deformation conditions unfavorable for twinning, del Valle and Ruano [55] showed that DRX is delayed for samples processed by ECAP whose texture strongly favors basal slip, while in rolled samples with textures that favors multiple slip a noticeable enhancement of DRX was reported.

The predominance of one or another DRX mechanism results in specific texture and grain size changes. Under DDRX conditions, the aforementioned bulging mechanism results in a recrystallization texture which is closely related to the deformation texture [55], because of the close orientation relationship between the new and old grains in the bulged zones [57]. On the contrary, the RDRX mechanism predicts a definite rotation of the new grains with respect to original grains. This phenomenon has been reported by Ion et al [46], invoked in several works $[59,60]$ and related to formation of shear bands during large strain hot rolling [15]. In case of DDRX a well defined relation between the grain size and the maximum stress (or Z) was reported [65]. A stress exponent of -1.56 was found, which correlates very well with the value obtained by Derby et al. [66] on a wide recompilation of metals and minerals. However, no definite relationship has been predicted for the RDRX mechanism so far.

\subsection{Large strain hot rolling (LSHR):}

In this section it will be shown how large strain hot rolling (LSHR) is a useful methodology for grain refinement in cast $\mathrm{Mg}$ alloys with random textures [21, 32, 53, 67] or even in rolled alloys with strong basal fiber textures. LSHR has also the additional benefit of decreasing the intensity of the basal texture of the processed Mg-alloys.

Let us first consider LSHR of Mg sheet alloys (fabricated by hot rolling or by rolling and annealing), such as AZ31 and AZ61, with equiaxed grain sizes of several tens of microns. Due to their strong texture, basal slip during further rolling (LSHR) is severely prevented, leading to early failure if thickness reductions higher than $30 \%$ are applied $[15,68]$. We have demonstrated 
that this can be avoided if the passes with more severe reductions are preceded by a first rolling pass with a small thickness reduction $(10 \%$ or $20 \%)$. In the following, the microstructural changes taking place during the multi-step LSHR process are described $[15,69]$.

Fig. 1 illustrates the microstructure of a bar of the AZ61 alloy, which is formed by equiaxed recrystallized grains with an average grain size of $54 \mu \mathrm{m}$. The as-received texture consists of a basal fiber (Fig. 2a). This alloy was processed using a rolling scheme consisting of three passes with $20 \%, 35 \%$, and $55 \%$ reductions, respectively. The textures after each pass are illustrated in Fig. 2b [15, 69]. A gradual weakening of the basal fiber texture was observed during processing. Simultaneously, the grain size decreases (Fig.3). Already during the first pass, a significant decrease of the basal fiber is observed. This is consistent with the operation of RDRX, which gives rise to new small grains with orientations more favorable for basal slip. Upon subsequent passes, the recrystallized grains tend to group forming paths of easy slip or ductile zones where basal slip becomes the main deformation mechanism (Figs. 4 and 5). Thus, large reductions per pass can be attained. Simultaneously, RDRX continues to operate, leading to an additional texture decrease. After very high reductions, only a few large grains will be left in the microstructure (Fig. 4). The estimated strain rate during large strain hot rolling falls in the range of 10-30 s-1. Therefore the Zener-Hollomon parameter should be relatively large, which is consistent with the operation of the RDRX mechanism. Large strain hot rolling could thus be a useful methodology for grain refinement and texture weakening in $\mathrm{Mg}$ alloys with an initial strong basal texture.

Let's now consider the LSHR of randomly oriented as-cast Mg alloys. Fig. 6 illustrates the microstructure of a cast solid solution treated AZ91 alloy [32]. It can be seen in Figs.6a and 6b that almost all of the second phase particles $\left(\mathrm{Mg}_{17} \mathrm{Al}_{12}, \beta\right.$-phase $)$ were dissolved and that some porosity exists. Fig. 6c shows the random texture of the alloy using the (0002), (10-10) and (1120) pole figures. Fig. 7 illustrates the microstructure of this alloy after one rolling pass at $673 \mathrm{~K}$ with the following thickness reductions: 30\% (Fig.7a), 50\% (Fig. 7b), 71\% (Fig. 7c) and 83\% (Fig. 7d). For reductions higher than 30\% some minor edge cracking was observed, which was removed by grinding of the edges. Therefore large reductions can be applied in the first pass in comparison with material with an initial basal texture. Fig. 7 illustrates that dynamic recrystallization takes place during hot deformation especially at high strains. For small deformations, significant twinning nucleation takes place, grain boundaries become wavy (indicating the slip activity) and small recrystallized grains are visible along some grain boundary areas and twinned regions (Figs. $7 \mathrm{a}$ and $7 \mathrm{~b}$ ). The volume fraction of recrystallized grains increases with increasing thickness reduction (Figs. 7c and 7d). Some large elongated grains remain present even after $83 \%$ deformation. The average recrystallized grain size slightly decreases with increasing deformation. At $83 \%$ thickness reduction, a recrystallized grain size of $1.4 \mu \mathrm{m}$ is achieved. Fig. 8 illustrates the evolution of the macrotexture with increasing strain. After a reduction of $30 \%$ a weak basal type texture develops (Fig. 8a) and no other texture components appear. With increasing rolling reduction the basal texture becomes better defined and the splitting of the basal peak becomes more apparent (Figs. $8 \mathrm{~b}$ to $8 \mathrm{~d}$ ). The two maxima are rotated approximately 140 from the normal direction (ND) towards the rolling direction (RD). This texture is stable during rolling and its intensity increases further during subsequent passes (Figs. $8 \mathrm{c}$ and $8 \mathrm{~d}$ ). It is interesting to note that the intensity of the texture developed is relatively weak compared with that of the initial hot rolled AZ61 sheet (Fig. 2a), and quite similar to the LSHR AZ61 alloy (Fig. 2b). This, again, suggests that the concurrent operation of RDRX during LSHR leads to weaker textures than conventional hot rolling.

In the following, the deformation and recrystallization mechanisms responsible for these microstructural changes are examined. In grains which have c-axis perpendicular to compression axis (normal direction of the rolled sheet, ND), twinning takes place at the earlier stages of deformation, tilting the basal plane by 860 and, therefore, giving rise to a weak basal texture (i.e., c-axis is parallel to the compression axis) (Figs. 8a and 8b). With increasing deformation (or thickness reduction), twin nucleation and twin propagation give rise to an increasingly strong basal texture. In addition, the grains which are favourably oriented for basal slip, rotate 
gradually until their c-axis is parallel to the compression axis. As a result of this process, after reaching approximately $50 \%$ of deformation the basal texture has been established. The key point is that recrystallization occurs massively from this point onwards and the process is considered to be similar to the previously described mechanism for the case of the textured AZ61. The overall evolution of the microstructure also resembles the description presented by Ion, White and Humphreys [46] for the RDRX. The basal planes of these recrystallized grains are rotated away from the rolling plane and thus basal slip might take place in them to a certain extent. Grain subdivision continues in a similar fashion with increasing strain until only a few large original grains are left. It can be assumed that recrystallized new grains also deform leading to some increase of the basal texture from an intensity of 4 to 6 . On the one hand, enhanced non-basal slip results in the formation of double peak in the RD [70]. Similar deformation mechanisms were also observed in various alloys after compression testing or after severe rolling [45, 47, 71].

In summary, LSHR of strongly textures Mg sheet alloys results in a decrease of grain size and in a weakening of the basal texture, as a consequence of the operation of RDRX, whereas in the case of randomly-textured alloys, LSHR first leads to the development of basal textures, and subsequently, to grain size refinement and texture weakening. Table 1. illustrates the grain sizes achieved using a large strain hot rolling process. The resulting grain sizes are similar to the grain sizes obtained by more sophisticated methods such as powder metallurgy [18] or even ECAE [72-74].

\subsection{Equal channel angular pressing (ECAP):}

ECAP is a severe plastic deformation technique that has been profusely used in the past 15 years $[75,76]$. In the following the microstructure evolution of some as-cast and as-rolled $\mathrm{Mg}$ alloys $[21,65,68]$ following one and two ECAP passes (routes A and C) with a die angle of 90o (inner) will be reviewed. Other ECAP processing conditions were extensively studied in the literature [77-81]. ECAP, like other severe plastic deformation techniques, aims to produce grain refinement by dynamic recrystallization, which, of course, occurs by one of the DRX mechanisms previously discussed.

Let's consider first an as-cast, solution heat treated AM60 alloy with an initial grain size of $15 \mu \mathrm{m}$ that is subjected to one ECAP pass at $523 \mathrm{~K}$, using a square die of $12 \mathrm{~mm}$ x $12 \mathrm{~mm}$, with an intersection angle of $\Phi=90^{\circ}$ and a plunger speed of $V=0.1 \mathrm{~mm} \mathrm{~s}^{-1}$. The processing strain rate $(\varepsilon)$, calculated from the expression given by Segal [82], i.e., $(20 V \cos (\theta)) / \mathrm{a})$, where $2 \theta=\Phi$, and $a$ is the billet thickness, is $\varepsilon \approx 0.1 \mathrm{~s}^{-1}$. Fig. 9 shows the microstructural evolution of such alloy at different locations during an interrupted ECAP pass. Before the material enters the shear zone (Fig. 9a), some twinning occurs due to the compression stress. As the material enters the shear zone (Fig. 9b), there is a strong bulging of grain boundaries and the first recrystallized grains evolve from this bulging process. The material that emerges from the shear zone (Fig. $9 \mathrm{c}$ ), shows a structure of shear bands oriented at 45 degrees with respect to ED, formed by small recrystallized grains and elongated original grains which have failed to recrystallize. This microstructural evolution resembles that resulting from LSHR (Fig. 7). In the present case, the recrystallization in the grain boundary appears to occur by the bulging mechanism (more related to DDRX) than by the rotation mechanism, RDRX. Regardless of the mechanism of formation of these new grains, the subsequent banding formation seems to follow the same pattern as in the case of LSHR. It is interesting to compare the micrographs in Fig. 9 with the work of Su et al. [83] for the AZ31 alloy deformed at 473K (plunger speed not reported). While Fig. 9 shows that the twinning plays a minor role in the recrystallization, Fig. 3 of $\mathrm{Su}$ et al. work shows extensive twinning, and recrystallization seems to be associated with it. In addition their micrographs show no bulging of grain boundaries. This demonstrates the sensitivity of the process of recrystallization to temperature, especially in the range where non basal slip activity increases.

Let us now consider a second ECAP pass by routes $\mathrm{A}$ and $\mathrm{C}$ at 523K [21]. Fig. 10 shows the corresponding microstructures and deformation textures. The second pass produces an 
increase of the recrystallized volume fraction without changing the recrystallized grain size. The evolution of the geometrical form of the original non-recrystallized grains follows the expected distortions introduced onto geometric elements for the routes A and C [20]. Route A produces an increase in the elongation of the grains. Conversely, during route $\mathrm{C}$ the direction of shear is reversed on each pass and the strain is restored after every even number of passes with no net shape change, thus, route $\mathrm{C}$ is termed a redundant strain. The texture evolution during ECAP of the AM60 alloy is shown in Figs. 10b and 10d. For route C, the (0002) pole figure reveals the formation of a maximum located at $45^{\circ}$ from ED towards TD indicating that the basal planes rotate during ECAP to a position parallel to the shear direction. As is well known [20], the operating slip planes after the first pass by route $\mathrm{C}$ are well oriented for the continuation of the strain in the next ECAP pass. Thus, their orientation remains stable. In contrast, the basal planes in route A must reorient themselves towards the imposed shear direction in each successive pass. Therefore, a dispersion of orientations occurs, as is shown in Fig. 10(b).

\subsection{Accumulative Roll Bonding (ARB):}

ARB is an SPD technique developed in the nineties that was meant to be more suitable for the fabrication at large sheets at an industrial scale [84]. It consists of several steps of rolling, cutting, piling-up, and, again rolling. During each rolling pass the different piled-up layers bond.

Figure 11 illustrates the evolution of the microstructure of an initially randomly oriented AZ91 alloy (as-cast and solution treated, with a grain size of $23 \mu \mathrm{m}$ ), after an ARB process consisting of 4 passes with $80 \%$ thickness reduction/pass [85]. Full bonding was achieved. The microstructure evolution is similar to that described above for the LSHR process. The grain size was reduced significantly during the first pass (Fig. 11a). The microstructure at this point consists of a very small fraction of coarse grains embedded in an ultrafine grained $(\mathrm{d}<1 \mu \mathrm{m})$ matrix. During the $2^{\text {nd }}, 3^{\text {rd }}$ and $4^{\text {th }}$ passes the volume fraction of recrystallized grains increases, but the grain size does not change (Figs. $11 \mathrm{~b}$ to $11 \mathrm{~d}$ ).

The ARB process can also be applied to textured samples [86]. The deformation mechanisms and final microstructures are similar to those activated in the randomly textured samples. Care must be, however, taken in order to give a preliminary treatment to the initial samples so as to accommodate the subsequent heavy reductions during the ARB process [86]. This preliminary treatment, already explained section 2.1 (LSHR), consists on applying a first pass with a smaller thickness reduction before proceeding with conventional ARB. It is interesting to highlight the considerable texture reduction that follows an ARB process, as demonstrated by Pérez-Prado et al. in [85]. Figs. 12a and 12b illustrate the texture of a hot-rolled AZ31 sheet before (Fig. 12a) and after (Fig. 12b) ARB. It is assumed that the reduction of texture is attributable to the mechanism of RDRX, already invoked for the LSHR processing. Fig. 12c shows the texture of a cast AZ91 alloy processed by ARB as described above. It can then seen that the intensity of the resulting texture is similar to that of the ARBed AZ31 alloy (Fig. 12b).

Finally it must be pointed out that, in order to achieve good bonding quality, the thickness reductions applied must be larger than 50\% [85-88]. It was shown that bonding takes place successfully at specific regions where the characteristic deformation bands intersected the bonding plane [86]. Moreover, it has been shown that the degree of bonding is better at higher temperatures and with larger rolling reductions. In particular, in the samples that were rolled at $400{ }^{\circ} \mathrm{C}$ using an $\mathrm{ARB}$ reduction of $80 \%$, the fraction of bonded interface is approximately $50 \%$.

\subsection{Effect of annealing:}

In this section, the work by Pérez-Prado et al. [89, 90] on annealing of $\mathrm{Mg}$ alloys is summarized. Fig. 13 illustrates the texture of an as-extruded AZ31 sheet alloy at the outer surfaces and at the mid-thickness [89]. The figure reveals the existence of a thickness texture gradient. In the mid-layer there are grains with $\{0002\}$ (basal), $\{10-10\}$ (prismatic) and $\{11-20\}$ 
(prismatic) planes parallel to the sheet plane (RP). The basal texture component predominates. However, in the regions close to the surface of the sheet, grains are oriented predominantly with only $\{11-20\}$ (prismatic) and $\{0002\}$ (basal) planes parallel to the RP. A close look at the intensity levels reveals that grains with $\{11-20\}$ planes parallel to the RP predominate. This texture gradient is attributed to shear deformation at the outer regions during processing. Fig. 14 shows the texture of this extruded AZ31 bar after annealing at $793 \mathrm{~K}$ for $3 \mathrm{~h}$. As a consequence of annealing, the $\{11-20\}$ (prismatic) texture component (planes $\{11-20\}$ parallel to the sheet plane) is strengthened in the mid layer and the $\{0002\}$ (basal) and $\{10-10\}$ (prismatic) components are retained. This suggests that the grains oriented with the $\{11-20\}$ plane parallel to the sheet plane grow mainly at the expense of randomly oriented grains. However, in the regions close to the surface, a dramatic change can be observed, as grains with $\{11-20\}$ planes parallel to the RP predominate, whereas those orientations with basal and prismatic $\{10-10\}$ planes parallel to the RP are absent. The microstructure (Fig. 3 in [89]) shows that in the surface region secondary recrystallization or abnormal growth takes place upon annealing. The texture data suggests that the grains that tend to grow abnormally are those oriented with planes $\{11-20\}$ parallel to the RP. After prolonged annealing times, a single component predominates, namely the $\{11-20\}[1-100]$. Thus, this is a stable orientation for abnormally growing grains in this AZ31 alloy. If the annealing temperatures are properly chosen it is possible to avoid secondary recrystallization.

Annealing following LSHR does not result in major texture changes [21, 49, 91]. An asextruded plate of an AZ61 alloy, $10 \mathrm{~mm}$ in thickness, was processed by severe hot rolling at 400 ${ }^{\circ} \mathrm{C}$ using two passes, the first to $7 \mathrm{~mm}$ and the second to $1.8 \mathrm{~mm}$ in thickness. The as-received texture was shown in Fig.2a. The texture of the as-rolled samples, which have a grain size of 3.6 $\mu \mathrm{m}$, is given in Fig. 15a. Subsequently, two separate annealing treatments were performed, 100 minutes at $300{ }^{\circ} \mathrm{C}$ and 1000 minutes at $400{ }^{\circ} \mathrm{C}$. The consequence of these treatments is the average grain size increases to $6.6 \mu \mathrm{m}$ and $36 \mu \mathrm{m}$, respectively, and that the texture weakens moderately (Figs. 15b and 15c) [24].

\section{Strength, ductility and superplasticity}

\subsection{Room temperature deformation}

Both the grain size and the texture affect considerably the yield strength. On the one hand, this magnitude follows a grain size dependence according the Hall-Petch relation. Magnesium is one of the metals having the largest ratio between the Hall-Petch slope and the shear modulus [92]. On the other hand the critical resolved shear stress (CRSS) of the different slip systems differs strongly as discussed in the Introduction. Therefore, plasticity usually starts with the activation of the basal system, with the lowest CRSS value, even in materials with a texture that is not fully favorable for basal slip as in the case of rolled materials $[9,93]$. In such way, the yield stress will be very sensitive to the Schmid orientation factor for basal slip.

As shown in previous sections, grain size and texture may be changing simultaneously during processing. For example, processing by ECAP produces a grain refinement that increases the resistance but, simultaneously, produces a texture that favors basal slip and thus reduces the resistance [94]. For this reason, it has been reported by several authors [95, 96] that occasionally tensile as well as compressive test results show deviations from the Hall-Petch relation.

In order to understand the yield stress dependence of the grain size, the best strategy is to fabricate samples with the same texture and different grain sizes, and study the corresponding variations in the yield stress. Del Valle et al. [21] processed an AZ31 alloy via LSHR and annealing treatments to achieve different grain sizes with the same texture. Fig. 16 shows the flow stress measured at a proof strain of $\varepsilon=0.002$ as a function of the grain size. The data follow a linear dependence on $\mathrm{d}^{-1 / 2}$, according to the Hall-Petch law: 


$$
\sigma_{0.2 \%}=\sigma o+k \mathrm{~d}-1 / 2
$$

The slope is $k=207 \mathrm{MPa} \mu \mathrm{m}^{1 / 2}$. The value of $k$ is close to that measured in the Mg [92] and AZ91 alloy [97, 98].

Another important mechanical property is ductility, which results from the work-hardening (WH) evolution with strain. The ductility in the case of rolled $\mathrm{Mg}$ samples is much smaller than that of ECAPed samples [34, 74, 99-103] due to the strong basal texture developed during rolling. In such circumstances basal slip is difficult and deformation has to be accommodated by either twinning or non-basal slip. Grain size and texture affect the work hardening rate in different ways. First, let's deal with the effect of grain size on work hardening. The work hardening rate is given as $\theta=\mathrm{d} \sigma / \mathrm{d} \varepsilon$, where $\sigma$ and $\varepsilon$ are the macroscopic true stress and true plastic strain, respectively. Fig. 17a shows tensile stress-strain curves corresponding to samples with various grain sizes, processed by performing annealing treatments to LSHR samples. The work hardening behaviour with varying grain size can be observed from Fig. 17b. The $\theta$ value decreases with stress in a linear fashion which resembles the well-known Stage III of fcc metals. In addition, $\theta$ decreases with decreasing grain size from 17 to $2 \mu \mathrm{m}$. However, the $\theta$ value for $\mathrm{d}=55 \mu \mathrm{m}$ is lower than for $17 \mu \mathrm{m}$ at the larger stresses. All the curves are quite parallel at room temperature. This indicates that there is a maximum value of $\theta$ for grain sizes near to $17 \mu \mathrm{m}$. Similar results were also observed in the literature [22, 104].

The literature on fcc metals [105] indicates that dynamic recovery is directly associated with the slope, of $\theta-\sigma$ curves, during stage III. Therefore, results of Fig $17 \mathrm{~b}$ indicates that dynamic recovery is independent of grain size. In contrast, the grain size affects the hardening extrapolation, $\theta^{\mathrm{III}}{ }_{\mathrm{o}}$, on Fig. $17 \mathrm{~b}$, producing a continuous decrease of $\theta^{\mathrm{III}} \mathrm{o}$ with decreasing grain size. When these results were published [94] two explanations of this behaviour were considered [94]. One is an increase of the contribution to deformation of grain boundary sliding (GBS) with decreasing grain size. One experimental fact that contradicts this argument is the observation that the grain size effect on $\mathrm{WH}$ is enhanced for orientations which favor multiple slip. Alternatively, it was also suggested that the decrease in WH could be related to changes in the relative activity of the slip systems when the grain size decreases. In a later paper [23] the effect of grain size on the strain rate sensitivity (SRS) was investigated. It was shown that the SRS increases strongly for grain sizes below $15 \mu \mathrm{m}$ (Fig. 17c). There is a close correlation between the SRS and the work hardening behavior. This result was interpreted as a favorable point on the direction of the increasing contribution of grain boundary sliding to deformation in fine grained samples.

However, strong evidence against the operation of GBS come shortly after through the measurement of the normal plastic anisotropy (r-value) [24, 25]. A study was made on the evolution of the normal anisotropy during tensile straining in the rolling direction and in the transverse direction (Fig. 18). Comparison of the sensitivity (Figs. 18a and 18b), anisotropy (Figs. $18 \mathrm{c}$ and 18d), and work hardening rate data shows a noticeable correlation in the trend of these three parameters. Coarse grained samples, produced with annealing treatments, present a noticeable decrease of the anisotropy, that is, the fine grained samples have the largest anisotropy. It is worth noting that these results are not compatible with an increasing amount of GBS in the fine grained material. Clearly, if a fine grain size enhances GBS, a decrease of anisotropy would be expected since this mechanism is mostly not affected by texture [16]

In summary, changes in the grain size produce a variation in $r$ which is an evidence of changes in the relative contributions of prismatic/basal slip. Our results show that these slip systems should have different strain rate sensitivities and microscopic work hardening rates. As their relative contributions change, an alteration of the macroscopic behavior of the sensitivities and the work hardening rate is obtained. These results highlight the variety of phenomena resulting from the application of severe plastic deformation techniques, such as LSHR, ECAP and $\mathrm{ARB}$, on the mechanical properties.

The most important effect of texture on the strength of $\mathrm{Mg}$ alloys is related to the tensioncompression asymmetry. This phenomenon has been connected with the mechanical twinning 
on the $\{10-12\}$ planes in the $<10-1-1>$ directions during compression but not in tension [6] as, for hexagonal crystals with $\mathrm{c} / \mathrm{a}<3^{1 / 2}$, the $\{10-12\}$ twinning mode produces tensile strains along the c-axis of the lattice but not compressive [106]. Due to the strong textures that are usually present in magnesium alloys and the polar nature of twinning, mechanical properties depend on the testing direction and the testing sense [8].

In order to understand the dependence of the work hardening rate on texture, a number of samples with the same grain size and different textures were prepared. Samples with a grain size of $15 \mu \mathrm{m}$ were processed through LSHR (denoted by R), ECAP-A (route A) and ECAP-C (route C) followed by heat treatment (ST) at $723 \mathrm{~K}$ for $30 \mathrm{~min}$ and water quenching in the case of AM60 alloy [21]. The texture of LSHR or R samples is similar to that shown in Fig. 8d, i.e., a dispersion of the c-axis around the normal direction, whereas the textures of ECAP-A and ECAP-C samples can be seen in Figs. 10c and 10d. Upon heat treatment (ST) no change in texture was observed but a slight spread occurred. Figs. 19a and 19b show the tensile stressstrain curves and their corresponding work hardening vs. stress curves for these three samples, respectively. First, an analysis of the macroscopic yield stress in terms of the critical resolved shear stress (CRSS) for basal slip on R-ST and ECAP-C+ST samples can be made. In the case of ECAP C samples, most of grains have the ideal orientation for slip on basal planes, i.e. the Schmid orientation factor is close to $\mathrm{m}_{\mathrm{sb}} \approx 0.5$, while in the case of R-ST samples most of the grains have the c-axis at about $15-20^{\circ}$ from the normal direction [21] leading to $\mathrm{m}_{\mathrm{sb}} \approx 0.33$. The yield stress in both samples corresponds to $\sigma=\tau \mathrm{b} / \mathrm{m}_{\mathrm{sb}}$, with $\tau \mathrm{b}$ being the CRSS for basal slip, that is, plasticity initiates with basal slip in both ECAP-C and R samples [21].

Clearly, there is a difference in the WH behaviour between the three samples analyzed and it must be attributed to a texture effect. Three regions of different work hardening behavior can be observed in the ECAP-C+ST stress-strain curve, and two in the case of ECAP-A+ST and $\mathrm{R}+\mathrm{ST}$ ones. Initially, there is a steep decrease in the hardening rate and it is due to a short elastoplastic transition. Next, in ECAP-C+ST samples, WH develops a stage II consisting of an almost constant hardening behavior; successively the curves show a stage III consisting of a decrease in the work hardening rate until necking and fracture. In the literature about fcc metals [105] stage II is correlated with single or double slip in polycrytalline metals with coarse grain size, while stage III is associated with multiple slip. Therefore, the appearance of stage II is consistent with the facilitation of basal slip in these samples. In the other two samples, ECAP-A+ST and R+ST the elasto-plastic transition is more extended, stage II is suppressed and stage III consist in a linear decrease of the WH rate as occurs in fcc metals [105]. This behavior is consistent with the operation of multiple slip by the addition of prismatic slip to the initial basal slip, immediately after the elasto-plastic transition.

From all of the above observations, the microscopic hardening mechanisms could be described as follows. At the beginning of deformation basal slip carries most of the strain. The microscopic hardening is that corresponding to this slip system and the differences in the initial macroscopic hardening rates are due to the orientation factors. With increasing strain, the rapid hardening of the basal systems causes the activation of prismatic systems if they have a high Schmid factor, such as in the case of the R+ST samples, in comparison to ECAP-C samples [21] leading to a rapid transition to stage III. Subsequently, multiple slip is activated, leading to a rapid decrease of the macroscopic hardening rate. It is deduced that the recovery events related to cross-slip may also be enhanced for samples with a texture that favours prismatic slip. It is interesting to compare these findings with the effect of grain size on WH. As mentioned previously, the decrease in the WH rate with decreasing grain size was linked to an increase in the activity of prismatic slip, because this is the most plausible explanation of the increase in normal anisotropy. Therefore, a congruent conclusion is reached here when performing the study of the texture effect on WH.

Finally, it is also interesting to evaluate the influence of texture on ductility. As is well known, necking begins in ductile metals at a maximum load where the increase in stress due to a decrease in cross-sectional area of the sample is larger than the load-carrying ability of the metal due to WH. This leads to the tensile instability condition: 


$$
\sigma=\frac{\mathrm{d} \sigma}{\mathrm{d} \varepsilon}
$$

This condition gives a straight line of slope one for a $\theta-\sigma$ plot. This line is shown in Fig. $19 \mathrm{~b}$ for the AM60 alloy. As can be seen, the deformation continues on all the processed samples until the instability condition is almost reached, as expected for ductile materials. In the case of the $\mathrm{R}+\mathrm{ST}$ and the ECAP-A+ST samples, the hardening capability worsens by the increase of prismatic slip, since dynamic recovery is probably also enhanced. This decrease in the hardening rate limits high deformations in comparison to ECAP-C+ST samples which can keep a constant hardening rate during all the stage II, which involves a considerable strain close to $10 \%$. The additional ductility in the ECAPed samples is provided by the presence of the stage II.

Since the processing routes described above allow fabricating $\mathrm{Mg}$ samples with very different grain sizes and textures, a wide variation in mechanical properties have been obtained. Fig. 20 illustrates the mechanical properties of AZ91 and AM60 alloys processed by ARB, LSHR and ECAP. The largest grain refinement $(\sim 0.5 \mu \mathrm{m})$ and, therefore, the highest yield (310 $\mathrm{MPa})$ and ultimate tensile strengths (405 MPa), were obtained using the ARB technique in the AZ91 alloy. The yield strength was increased 3 times with respect to the as-received material. However, the total elongation to failure $(\sim 2 \%)$ was low (Fig. 20a). This value is comparable to the strength values achieved by more expensive techniques such as those based on powder metallurgy [107]. The simultaneous enhancement of the yield strength and the ductility can be achieved using other processing routes such as LSHR and ECAP (Figs. 20b, 20c, and 20d). Table 2 shows the comparison of mechanical properties for various $\mathrm{Mg}$-Al alloys processed through different techniques.

\subsection{High temperature deformation}

The present authors carried out several high temperature studies in $\mathrm{Mg}$ alloys with the aim of understanding the micromechanisms predominant during high temperature plasticity. On one hand, these studies have been devoted to fundamental aspects such as the influence of texture and grain size on the different creep mechanisms, and the existence of thresholds stresses for them $[16,94,108]$. On the other hand, several studies were devoted to practical aspects about the development of microstructures capable of undergoing superplastic deformations. Various efforts have been devoted to investigate the superplastic conditions for sheet processed by LSHR $[69,109]$. In addition the thermal stability of the microstructures obtained by severe plastic deformation processes have been discussed with the aim of obtaining the optimum superplastic conditions $[68,110]$. Finally, the effect of microstructural heterogeneities on the superplastic capability of the magnesium alloys has been analyzed and modeled [111,112]. Determination of steady state stress data at high temperature for a given set of strain rates under the condition of constant microstructure is difficult, as significant microstructural changes (grain growth, texture changes) take place during testing. These problems can be overcome by the use of a strain rate change technique and by performing the study on samples with grain sizes larger than $10 \mu \mathrm{m}$ (where only limited grain growth takes place).

Figs. 21 and 22 illustrate the high temperature mechanical behaviour of an AM60 alloy having different grain sizes (larger than $10 \mu \mathrm{m}$ ) with same texture and with different textures and almost similar grain sizes [16]. Fig. 21 shows an example of the stress-strain data determination by means of strain rate change tests. Fig. 22 shows the strain rate against the Young modulus compensated stress for the AM60 cast+solution treated (ST) (random texture), $\mathrm{R}$ (LSHR processed + annealed) (basal texture) and EC (Route C + annealed) (basal planes rotated $45^{\circ}$ from the tensile axis) samples between $473 \mathrm{~K}$ and $723 \mathrm{~K}$. The influence of the grain size was mainly investigated on the LSHR samples (with d varying between 10 and $30 \mu \mathrm{m}$ ).

The mechanical behaviour of metallic materials during creep at high temperatures is 
generally described by the following power law relation between the strain rate, and the stress, $\sigma[113,114]$ :

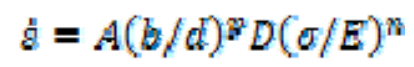

where $\mathrm{A}$ is a material constant, $\mathrm{E}$ is Young's modulus, $\mathrm{D}=\mathrm{D}_{\mathrm{o}} \exp (-\mathrm{Q} / \mathrm{RT})$ is the appropriate diffusion coefficient, $\mathrm{Q}$ is the activation energy, $\mathrm{R}$ is the gas constant, $\mathrm{T}$ is the absolute temperature, $\mathrm{b}$ is the magnitude of the Burgers vector, $\mathrm{d}$ is the grain size, $\mathrm{n}$ is the stress exponent and $\mathrm{p}$ is the grain size exponent. When GBS dominates, $\mathrm{n}=2, \mathrm{p}=2$ or 3 , and $\mathrm{Q}=\mathrm{Q}_{\mathrm{L}}$ (activation energy for lattice self-diffusion) or $\mathrm{Q}=\mathrm{Q}_{\mathrm{gb}}$ (activation energy for grain boundary diffusion). On the other hand, at large strain rates, stress exponents larger than $n=5$ are usually found in magnesium alloys. Several specific mechanisms have been proposed in such situations, taking into account the measured activation energies, including diffusion-controlled dislocation climb and cross-slip controlled slip creep. Irrespective of these mechanisms, no grain size dependence is expected in this stress range.

In Fig. 22, two stress exponent regimes can be distinguished. In the low stress exponent regime, at low strain rates and temperatures above $573 \mathrm{~K}, \mathrm{n}$ is close to 2 , which corresponds to the GBS mechanism [113]. Below this temperature, increasing stress exponents are obtained at 523 and $473 \mathrm{~K}$, and the low exponent regime progressively disappears. In contrast, in the high stress exponent regime, the stress exponents increase from 3 to 12 as temperatures decrease from 723 to $423 \mathrm{~K}$. In this regime, the stress depends strongly on the previous processing, especially at the lower temperatures $(473,523$ and $573 \mathrm{~K})$. A noticeable grain size dependence becomes evident with increasing temperature. In the low stress exponent regime, the value of $p$ can be found by plotting $\sigma / E$ vs. grain size at a fixed strain rate and for a fixed texture (as shown in Fig. $23 a)$. Using this $\mathrm{p}$ value the compensated strain rate, $\dot{s}(d / b)^{\mathfrak{F}}$ vs. $\sigma / \mathrm{E}$ graph was plotted to evaluate the texture effect alone (Fig. 23b). Finally, the activation energy can be calculated from the graph $\sigma / \mathrm{E}$ vs $1 / \mathrm{T}$ (Fig. 23c). The activation energy, in the regime with $\mathrm{n} \approx 2$, was found to be $91 \pm 2 \mathrm{~kJ} / \mathrm{mol}$ which is close to the activation energy for grain boundary diffusion of $\mathrm{Mg}$, suggesting GBS is the controlling mechanism. An important conclusion is that the texture has no effect in the regime of $n=2$, because irrespective of the R, EC or cast samples they all fall on a single line at a particular temperature (Fig. 23b). Conversely, in the high stress regime, the flow stress depends on the orientation of the basal planes with respect to the tensile axis, at the temperatures 473,523 and $573 \mathrm{~K}$. For instance, at $473 \mathrm{~K}$ and for grain sizes in the range 18-20 $\mu \mathrm{m}$, the R samples show stresses that are 30\% larger than the EC samples, while the Cast $+\mathrm{ST}$ samples show stresses that are 10\% larger than the EC samples. It was also found that the stress exponents are insensitive to the texture of the samples. Therefore data from samples with different textures can be put into coincidence by introducing a multiplicative factor. Del Valle and Ruano [16] have shown that this factor is the ratio of the corresponding Schmid factors for basal slip. Thus, the texture effect may be rationalized in terms of the strong tendency to deform predominantly by the activation of basal slip. Similar results were reported in [115-117]. However, at $648 \mathrm{~K}$ the data for $\mathrm{R}$ samples $(\mathrm{d}=18.7 \mu \mathrm{m})$ and $\mathrm{EC}$ samples $(\mathrm{d}=19.5 \mu \mathrm{m})$ coincide. This result indicates that the texture effect disappears when the temperature is increased from 573 to $648 \mathrm{~K}$. This disappearance was attributed to the increasing activity of multiple slip and, at the higher temperatures, to an increasing contribution of GBS [16]. Moreover, it has been shown that, in the high strain rate range, there is a decrease of the stress exponent with increasing temperature. Simultaneously, there is an increasing grain size effect. Most of these findings were congruently explained in [16] considering two contributions to creep, one from crystallographic slip and the other of GBS, by the use a modification of the Ghosh and Raj model [118] which accounts for the grain size distribution.

As it is well known, in fine-grained materials produced by SPD techniques, the strain rate increases according to equation (1) and the GBS mechanism wins in competitiveness against the slip creep mechanism, which has a higher stress exponent. The beneficial effect of increasing the GBs is to get a material with a high strain rate sensitivity (or low stress exponent) of the flow 
stress. From a mechanistic point of view, the tendency to develop a necking decreases strongly as sensitivity increases $[119,120]$. Reasonably large elongations of the order of $200 \%$, which are relevant for most forming operations, may be obtained easily by the processing of the microstructure by one of the severe plastic deformation techniques. For example, it has been shown that LSHR allows developing microstructures that show significant superplastic elongations in the low temperature range and at moderate strain rates as shown in Fig. 24 [69].

In the following we will examine the challenges that must be faced in order to use $\mathrm{Mg}$ alloys for practical forming operations. The mere obtaining of the finest possible grain size is not sufficient to ensure the practical feasibility of the process, as significant grain growth might occur already during temperature stabilization prior to forming. Optimization of a forming process thus requires a global approach to control microstructure stability and the deformation mechanisms operative under the forming conditions using the capabilities of the presses available [109,110]. Let's first examine the thermal stability of the Mg AZ31 alloy. Fig. 25 shows the value of the average grain size with different static annealing treatments. As can be seen, the low stability of the fine microstructures obtained by SPD techniques in the AZ31 alloy prevents the use of temperatures above about $473 \mathrm{~K}$. The initial grain size is stable up to $423-$ $473 \mathrm{~K}$. Beyond this temperature pronounced grain growth occurs in the $0.7 \mu \mathrm{m}$ samples. With gradually increasing temperature, the grains of the alloy with coarser initial grain sizes also grow steeply. For an initial grain size of $2.6 \mu \mathrm{m}$ the grain growth rate is lower compared to the grain size of $0.5 \mu \mathrm{m}$ at $573 \mathrm{~K}$ for $30 \mathrm{~min}$. Second, it is possible to draw a line, termed the limit temperature $\mathrm{T}_{\mathrm{L}}(\mathrm{d})$, which marks a limit for fast grain growth. The forming temperature must be below but close to $T_{L}(d)$ in order to preserve microstructural stability. The stability of the grains depends also on the prior processing. For example, fine-grained microstructures fabricated by ECAP are more stable than those produced by conventional rolling or by LSHR. Therefore the limit temperature also depends on the specific thermomechanical route utilized to process each alloy.

The optimum forming temperature which maximizes the ductility (in samples with a specific grain size), is the maximum temperature, $T_{L}(d)$, that can be used without noticeable grain growth. Grain growth leads, first, to an increase of the flow stress according equation (1). Secondly, grain growth enforces a change in the deformation mechanism to slip creep, which is characterized by a larger stress exponent, $n \geq 5$. This causes a loss in superplastic ductility of the material.

It must also be taken into account that the capabilities of the presses available impose some limits in the attainable strain rates and stresses. For example, the blow forming of cups of $15 \mathrm{~mm}$ of radius from sheets of $1.5 \mathrm{~mm}$ thickness must be performed using gas pressures lower than about $1 \mathrm{MPa}$. In general, realistic blow forming conditions are equivalent to deforming the material at a strain rate larger than 10-4 s $\mathrm{s}^{-1}$ and stresses smaller than $10 \mathrm{MPa}$. These conditions are highlighted in the so-called regions of interest (ROI) of Figs. 26a and b, which illustrate several stress-strain rate data for the AZ31 alloy with different grain sizes. In Figs. 26c and 26d the elongations to failure are given as a function of the strain rate. As it can be seen, for $\mathrm{d}=17$ $\mu \mathrm{m}$ it is possible to obtain elongations of $250 \%$, at $\mathrm{T}=523 \mathrm{~K}$ for a strain rate of $2 \times 10-4 \mathrm{~s}^{-1}$ inside the ROI. For $\mathrm{d}=4 \mu \mathrm{m}$ it is possible to obtain elongations of $250 \%$ at $\mathrm{T}=673 \mathrm{~K}$ and a strain rate close to $2 \times 10-4 \mathrm{~s}^{-1}$ inside the ROI. However for $\mathrm{d}=0.7 \mu \mathrm{m}$ it is not possible to increase the temperature beyond $423 \mathrm{~K}$ without harmful grain growth. Although it is possible to reach $500 \%$ elongation, at strain rate close to $2 \times 10-4 \mathrm{~s}^{-1}$, the required applied stress is close to $100 \mathrm{MPa}$, a value which falls out of the ROI. Indeed, a very fine grain size may be useless if stresses near to $100 \mathrm{MPa}$ are required to carry out a forming process to prevent grain growth. The analysis performed in $[109,110]$ shows that the best strategy to perform superplastic blow forming in magnesium alloys is to use grain sizes in the micron range and high forming temperatures, since then deformation is still controlled by GBS and elongations to failure larger than $200-300 \%$ can be obtained using the moderate flow stresses that can be applied using conventional presses.

Another factor that must be considered when examining the feasibility of superplatic 
forming of $\mathrm{Mg}$ alloys are microstructural heterogeneities. The latter might arise in various ways. For example, during SPD thermomechanical processing, recrystallization either by RDRX or DDRX frequently produces bimodal grain boundary distributions. The local influence of bimodal grain size distributions on the superplastic behavior was investigated and modeled in [111]. An iso-strain model, considering that each grain deforms at the imposed macroscopic strain rate, allows the major experimental observations to be readily explained and predicted. The influence of large-scale heterogeneities in the grain size on ductility was also analyzed in the superplastic regime [112]. It was demonstrated that these fluctuations could lead to premature necking. In case of large strain hot rolling, it was found that neck formation is related to bands of fine grains that are formed during rolling. Under these circumstances, grain refinement could produce unsuccessful results from the point of view of superplatic forming. Therefore, techniques such as LSHR must be optimized to obtain grain refinement while avoiding too much strain localization.

\section{Conclusions}

This paper reviews the work by the authors on the influence of the thermomechanical processing on the grain size, the texture and the mechanical behaviour of $\mathrm{Mg}-\mathrm{Al}$ alloys. The potential for grain refinement of three different processing techniques (large strain hot rolling (LSHR), equal channel angular pressing (ECAP) and accumulative roll bonding (ARB)) is analyzed. All these processing routes can be used to achieve sub-micrometer or micrometer grain sizes by properly choosing the processing variables irrespective of the initial texture of the sample. Basal textures with a certain degree of splitting were observed in samples processed by LSHR and ARB. In ECAP-processed samples the texture depends on the processing route and on the number of passes. Post-processing annealing at moderate temperatures and times has no effect in changing the texture of processed samples by these three routes although a slight spread in the texture can be observed. At high temperatures and prolonged times, secondary or abnormal recrystallization takes place. By properly tuning the post-processing annealing temperature it is possible to achieve a wide range of grain sizes above micrometer level after these three processes.

Decreasing the grain size for a particular texture or producing textures with basal planes containing the tensile axis for a particular grain size, result a decrease in the work hardening behaviour of the samples, indicating the activation of multiple slip. Changes in the texture may result in deviations from the Hall-Petch relation. Therefore by choosing the proper processing variables it is possible to achieve suitable grain sizes and somewhat controlled textures which result in very high strength as well as good ductility at room temperature.

The conditions under which $\mathrm{Mg}$ alloys could be used successfully in blow forming operations are discussed. For example, it was found that a microstructure, with a grain size of 5$20 \mu \mathrm{m}$, allows the better conditions for blow forming the AZ31. In this way significant grain growth during operation at $400{ }^{\circ} \mathrm{C}$ is prevented, superplastic elongations are obtained, and both the strain rate and stresses needed for fulfill the process are achievable with the conventional presses available. This kind of microstructure can be obtained with the LSHR processing discussed along this work. 
J.A.V. and O.A.R. are thankful to the CICYT-Spain within the framework of the project MAT2009-14452. B.S.R. is thankful to the AMOROUT project FP7 Marie Curie Action People COFUND Programme. The authors would like to thank the vehicle interior manufacturer, Grupo Antolin Ingenieria, S.A., within the framework of the project MAGNO2008-1028-CENIT Project funded by the Spanish Ministry as well as the ESTRUMAT-S2009/MAT-1585 grant (Madrid Regional Government).

\section{References}

[1] Mordike, B.L. -Ebert, T.: Mater. Sci. Eng. A, 302, 2001, p. 37.

[2] Avedesian, M. -Baker, H.: ASM Specialty Handbook Magnesium and Magnesium alloys. Materials Park, OH, ASM International 1999.

[3] Roberts, C.S.: Magnesium and its alloys. New York, Wiley 1960.

[4] Reed-Hill, R.E. -Robertson, W.D.: Trans. TMS-AIME, 220, 1957, p. 496.

[5] Jain, A. -Agnew, S.R.: Mat. Sci. Eng. A, 462, 2007, p. 29.

[6] Agnew, S.R. -Tomé, C.N. -Brown, D.W. -Holden, T.M. -Vogel, S.C.: Scr. Mater., 48, 2003, p. 1003.

[7] Stanford, N. -Barnett, M.R.: Mater. Sci. Eng. A, 516, 2009, p. 226.

[8] Proust, G. -Tomé, C.N. -Jain, A. -Agnew, S.R.: Inter. J. Plast., 25, 2009, p. 861.

[9] Yi, S.B. -Davies, C.H.J. -Brokmeier, H.G. -Bolmaro, R.E. -Kainer, K.U. -Homeyer, J.: Acta Mater., 54, 2006, p. 549.

[10] Hauser, F.E. -Landon, P.R. -Dorn, J.E.: Trans. Amer. Soc. Met., 50, 1958, p. 856.

[11] Chino, Y. -Kado, M. -Mabuchi, M.: Mater. Sci. Eng. A, 494, 2008, p. 343.

[12] McDonald, J.C.: Trans. Metall. Soc. AIME, 137, 1940, p. 430.

[13] Yang, Z. -Li, J.P. -Zhang, J.X. -Lorimer, G.W. -Robson, J.: Acta Metall. Sin., 21, 2008, p. 313.

[14] Mukai, T.: National Institute for Materials Science, Tsukuba, Japan, Private Communications, 2002. 
[15] Del Valle, J.A. -Pérez-Prado, M.T. -Ruano, O.A.: Mater. Sci. Eng. A, 355, 2003, p. 68. [16] Del Valle, J.A. -Ruano, O.A.: Acta Mater., 55, 2007, p. 455.

[17] Kubota, K. -Mabuchi, M. -Higashi, K.: J. Mater. Sci., 34, 1999, p. 2255.

[18] Mabuchi, M. -Asahina, T. -Iwasaki, H. -Higashi, K.: Mater. Sci. Tech., 13, 1997, p. 825.

[19] Furukawa, M. -Horita, Z. -Nemoto, M. -Langdon, T.G.: Mater. Sci. Eng. A, 324, 2002, p. 82.

[20] Valiev, R.Z. -Islamgaliev, R.K. -Alexandrov, I.V.: Prog. Mater. Sci., 45, 2000, p. 103.

[21] Del Valle, J. A. -Carreño, F. -Ruano, O.A.: Acta Mater., 54, 2006, p. 4247.

[22] Barnett, M.R. -Keshavarz, Z. -Beer, A.G. -Atwell, D.: Acta Mater., 52, 2004, p. 5093.

[23] Del Valle, J.A. -Ruano, O.A.: Scr. Mater., 55, 2006, p. 775.

[24] Del Valle, J.A. -Ruano, O.A.: Mater. Lett., 63, 2009, p. 1551.

[25] Del Valle, J.A. -Ruano, O.A.: Mater. Sci. For., 638-642, 2010, p. 1524.

[26] Meyers, M.A. -Vöhringer, O. -Lubarda, V.A.: Acta Mater., 49, 2001, p. 4025.

[27] Hwang, S. -Nishimura, C. -McCormick, P.G.: Scr. Mater., 44, 2001, p. 1507.

[28] Choi, H.J. -Kim, Y. -Shin, J.H. -Bae, D.H.: Mater. Sci. Eng. A, 527, 2010, p. 1565.

[29] Mallick, A. -Vedatam, S. -Lu, L.: Mater. Sci. Eng. A, 515, 2009, p. 14.

[30] Lu, L. -Raviprasad, K. -Lai, M.O.: Mater. Sci. Eng. A, 368, 2004, p. 117.

[31] Barnett, M.R. -Nave, M.D. -Bettles, C.J.: Mater. Sci. Eng. A, 386, 2004, p. 205.

[32] Del Valle, J.A. -Pérez-Prado, M.T. -Bartolomé, J.R. -Peñalba, F. -Ruano, O.A.: Mater. Trans., 44, 2003, p. 2625.

[33] Bonarski, B.J. -Schafler, E. -Mingler, B. -Skrotzki, W. -Mikulowski, B. -Zehetbauer, M.J.: J. Mater. Sci., 43, 2008, p. 7513.

[34] Mukai, T. -Yamanoi, M. -Watanabe, H. -Higashi, K.: Scr. Mater., 45, 2001, p. 89.

[35] Kim, W.J. -Jeong, H.T.: Mater. Trans., 46, 2005, p. 251. 
[36] Barnett, M.R. -Stanford, N. -Cizek, P. -Beer, A. -Xuebin, Z. -Keshavarz, Z.: JOM, 61, 2009, p. 19.

[37] Stanford, N.: Mater. Sci. Eng. A, 527, 2010, p. 2669.

[38] Mackenzie, L.W.F. -Pekguleryuz, M.O.: Scr. Mater., 59, 2008, p. 665.

[39] Stanford, N. -Barnett, M.R.: Mater. Sci. Eng. A, 496, 2008, p. 399.

[40] Kim, W.J. -Lee, J.B. -Kim, W.Y. -Jeong, H.T. -Jeong, H.G.: Scr. Mater., 56, 2007, p. 309.

[41] Kim, S.H. -You, B.S. -Yim, C.D. -Seo, Y.M.: Mater. Lett., 59, 2005, p. 3876.

[42] Kim, W.J. -Park, J.D. -Kim, W.Y.: J. Alloys Comp., 460, 2008, p. 289.

[43] Bohlen, J. -Yi, S. -Letzig, D. -Kainer, K.U. : Mater Sci Eng., 527, 2010, p.7092.

[44] Dieter, G.E.: Mechanical Metallurgy. United Kingdom, McGraw-Hill Book company (UK) Limited 1988.

[45] Myshlyaev, M.M. -McQueen, H.J. -Mwembela, A. -Konopleva, E.: Mater. Sci. Eng. A, 337, 2002, p. 121.

[46] Ion, S.E. -Humphreys, F.J. -White, S.H.: Acta Metall., 30, 1982, p. 1909.

[47] Beer, A.G. -Barnett, M.R.: Metall. Mater. Trans. A, 38, 2007, p. 1856.

[48] Barnett, M.R.: J. Light Met., 1, 2001, p.167.

[49] Barnett, M.R.: Mater. Trans., 44, 2003, p. 571.

[50] Beer, A.G. -Barnett, M.R.: Mater. Sci. Eng. A, 423, 2006, p. 292.

[51] Sitdikov, O. -Kaibyshev, R.: Mater. Trans., 42, 2001, p. 1928.

[52] Sitdikov, O. -Kaibyshev, R. -Sakai, T.: Mater. Sci. For., 419-422, 2003, p. 521.

[53] Pérez-Prado, M.T. -Del Valle, J.A. -Contreras, J.M. -Ruano, O.A.: Scr. Mater., 50, 2004, p. 661.

[54] Gehrmann, R. -Frommert, M.M. -Gottstein, G.: Mater. Sci. Eng. A, 395, 2005, p. 338.

[55] Del Valle, J.A. -Ruano, O.A.: Mater. Sci. Eng. A, 487, 2008, p. 473. 
[56] Galiyev, A. -Kaibyshev, R. -Gottstein, G.: Acta Mater., 49, 2001, p. 1199.

[57] Humphreys, F.J. -Hatherly, M.: Recrystallization and Related Annealing Phenomena, second ed., Elsevier, Oxford, UK, 2004.

[58] Gourdet, S. -Montheillet, F.: Acta Mater., 51, 2003, p. 2685.

[59] Yi, S.B. -Zaefferer, S. -Brokmeier, H.G.: Mater. Sci. Eng. A, 424, 2006, p. 275.

[60] Ulacia, I. -Dudamell, N.V. -Gálvez, F. -Yi, S. -Pérez-Prado, M.T. -Hurtado, I.: Acta Mater., 58, 2010, p. 2988.

[61] Mwembela, A. -Konopleva, E.B. -McQueen, H.J.: Scr. Mater., 37, 1997, p. 1789.

[62] Barnett, M.R. -Beer, A.G. -Atwell, D. -Oudin, A.: Scr. Mater., 51, 2004, p. 19.

[63] Tan, J.C. -Tan, M.J.: Mater. Sci. Eng. A, 339, 2003, p. 124.

[64] Yang, X. -Miura, H. -Sakai, T.: Mater. Trans., 44, 2003, p. 197.

[65] Del Valle, J.A. -Ruano, O.A.: Mater. Sci. Eng. A, 487, 2008, p. 473.

[66] Derby, B: Acta Metall. Mater., 39, 1991, p. 955.

[67] Pérez-Prado, M.T. -Del Valle, J.A. -Ruano, O.A.: Mater. Lett., 59, 2005, p. 3299.

[68] Eddahbi, M. -Del Valle, J.A. -Pérez-Prado, M.T. -Ruano, O.A.: Mater. Sci. Eng. A, 410411, 2005, p. 308.

[69] Pérez-Prado, M.T. -Del Valle, J.A. -Ruano, O.A.: Mater. Sci. For., 447-448, 2004, p. 221.

[70] Agnew, S.R. -Yoo, M.H. -Tomé, C.N.: Acta Mater., 49, 2001, p. 4277.

[71] Ding, H. -Hirai, K. -Kamado, S.: Mater. Sci. Eng. A, 527, 2010, p. 3379.

[72] Mabuchi, M. -Iwasaki, H. -Yanase, K. -Higashi, K.: Scr. Mater., 36, 1997, p. 681.

[73] Yoshida, Y. -Yamada, H. -Kamado, S. -Kojima, Y.: J. Japan Inst. Light Met., 51, 2001, p. 551.

[74] Kim, W.J. -Hong, S.I. -Kim, Y.S. -Min, S.H. -Jeong, H.T.: Acta Mater., 51, 2003, p. 3293.

[75] Segal, V.M. -Reznikov, V.I. -Drobyshevkij, A.E. -Kopylov, V.I.: Metally, 1, 1981, p. 115. 
[76] Beyerlein, I.J. -Tóth, L.S.: Prog. Mater. Sci., 54, 2009, p. 427.

[77] Kim, H.K. -Kim, W.J.: Mater. Sci. Eng. A, 385, 2004, p. 300.

[78] Koike, J. -Kobayashi, T. -Mukai, T. -Watanabe, H. -Suzuki, M. -Murayama, K. Higashi, K.: Acta Mater., 51, 2003, p. 2055.

[79] Yoshida, Y. -Arai, K. -Shota, I. -Kamado, S. -Kojima, Y.: Sci. Tech. Adv. Mater., 6, 2005 , p. 185.

[80] Agnew, S.R. -Mehrotra, P -Lillo, T.M. -Stoica, G.M. -Liaw, P.K.: Acta Mater., 53, 2005, p. 3135 .

[81] Figueiredo, R.B. -Beyerlein, I.J. -Zhilyaev, A.P. -Langdon, T.G.: Mater. Sci. Eng. A, 527, 2010, p. 1709.

[82] Segal, V.M.: Mater. Sci. Eng. A, 386, 2004, p. 269.

[83] Su, C.W. -Lu, L. -Lai, M.O.: Mater. Sci. Eng. A, 434, 2006, p. 227.

[84] Saito, Y. -Utsunomiya, H. -Tsuji, N. -Sakai, T.: Acta Mater., 47, 1999, p. 579.

[85] Pérez-Prado, M.T. -Del Valle, J.A. -Ruano, O.A.: Scr. Mater., 51, 2004, p. 1093.

[86] Del Valle, J.A. -Pérez-Prado, M.T. -Ruano, O.A.: Mater. Sci. Eng. A, 410-411, 2005, p. 353.

[87] Zhan, M.Y. -Li, Y.Y. -Chen, W.P.: Nonferrous Met. Soc. China, 18, 2008, p. 309.

[88] Wang, Q.F. -Xiao, X.P. -Hu, J. -Xu, W.W. -Zhao, X.Q. -Zhao, S.J.: Proc. Sino-Swedish Struct. Mater. Symp., 2007, p. 167.

[89] Pérez-Prado, M.T. -Ruano, O.A.: Scr. Mater., 46, 2002, p. 149.

[90] Pérez-Prado, M.T. -Ruano, O.A.: Scr. Mater., 48, 2003, p. 59.

[91] Yang, Q. -Ghosh, A.K.: Acta Mater., 54, 2006, p. 5159.

[92] Armstrong, R. -Codd, I. -Douthwaite, R.M. -Petch, N.J.: Philos. Mag., 7, 1962, p. 45.

[93] Wang, H. -Raeisinia, B. -Wu, P.D. -Agnew, S.R. -Tomé, C.N.: Inter. J. Solids Struct., 47, 2010, p. 2905.

[94] Del Valle, J.A. -Carreño, F. -Ruano, O.A.: Scr. Mater., 57, 2007, p. 829. 
[95] Trojanova, Z. -Lukác, P.: J. Mater. Proc. Tech., 162, 2005, p. 416.

[96] Trojanova, Z. -Caceres, C.H. -Lukác, P. -Cizek, L.: Kovove Mater., 46, 2008, p. 249.

[97] Mabuchi, M. -Chino, Y. -Iwasaki, H. -Aizawa, T. -Higashi, K.: Mater. Trans., 42, 2001, p. 1182 .

[98] Nussbaum, G. -Sainfort, P. -Regazzoni, G. -Gjestland, H.: Scr. Metall., 23, 1989, p. 1079.

[99] Ding, S.X. -Lee, W.T. -Chang, C.P. -Chang, L.W. -Kao, P.W.: Scr. Mater., 59, 2008, p. 1006.

[100] Masoudpanah, S.M. -Mahmudi R.: Mater. Design, 31, 2010, p. 3512.

[101] Jin, L. -Lin, D. -Mao, D. -Zeng, X. -Ding, W.: Mater. Lett., 59, 2005, p. 2267.

[102] Agnew, S.R. -Horton, J.A. -Lillo, T.M. -Brown, D.W.: Scr. Mater., 50, 2004, p. 377.

[103] Mathis, K. -Mussi, A. -Trojanova, Z. -Lukác, P. -Rauch, E.: Kovove Mater., 41, 2003, p. 293.

[104] Jain, A. -Duygulu, O. -Brown, D.W. -Tomé, C.N. -Agnew, S.R.: Mater. Sci. Eng. A, 486, 2008, p. 545.

[105] Sevillano, J.G.: Mater. Sci. Tech. New York (NY), VCH 1993.

[106] Yoo, M.F.: Metall. Trans. A, 12, 1981, p. 409.

[107] Jones, H.: Mater. Sci. Eng. A, 137, 1991, p. 77.

[108] Del Valle, J.A. -Pérez-Prado, M.T. -Ruano, O.A.: Metall. Mater. Trans. A, 36, 2005, p. 1427.

[109] Pérez-Prado, M.T. -Del Valle, J.A. -Salort, F. -Peñalba, F. -Gómez, X. -Ruano, O.A.: Mater. Sci. Tech., 23, 2007, p. 444.

[110] Del Valle, J.A. -Peñalba, F. -Ruano, O.A.: Mater. Sci. Eng. A, 467, 2007, p.165.

[111] Del Valle, J.A. -Ruano, O.A.: Mater. Lett., 62, 2008, p. 3391.

[112] Del Valle, J.A. -Ruano, O.A.: Mater. Sci. Tech., 24, 2008, p. 1238.

[113] Ruano, O.A. -Sherby, O.D.: Rev. Phys. Appl., 23, 1988, p. 625.

[114] Ruano, O.A. -Miller, A.K. -Sherby, O.D.: Mater. Sci. Eng., 51, 1981, p. 9. 
[115] Hsu, S. -Edwards, G.R. -Sherby, O.D.: Acta Metall., 31, 1983, p. 763.

[116] Edwards, G.R. -McNelley, T.R. -Sherby, O.D.: Scr. Metall., 8, 1974, p. 475.

[117] Milička, K. -Dobeš, F. -Pérez, P. -Garcés, G. -Adeva, P.: Scr. Mater., 61, 2009, p. 1109.

[118] Ghosh, A.K. -Raj, R.: Acta Metall., 29, 1981, p. 607.

[119] Avery, D.H. -Stuart, J.M.: Proc. 14th Sagamore Army Materials Research Conf., Raquette Lake, New York (USA), August 1967, 371.

[120] Edington, J.W. -Melton, K.N. -Cutler, C.P.: Prog. Mater. Sci., 21, 1976, p. 61.

[121] Chino, Y. -Mabuchi, M.: Adv. Eng. Mater., 3, 2001, p. 981.

[122] Mabuchi, M. -Chino, Y. -Iwasaki, H.: Mater. Trans., 44, 2003, p. 490.

[123] Lin, H.K. -Huang, J.C. -Langdon, T.G.: Mater. Sci. Eng. A, 402, 2005, 250.

[124] Chung, S.W. -Higashi, K. -Kim, W.J.: Mater. Sci. Eng. A, 372, 2004, p. 15.

[125] Chang, T.C. -Wang, J.Y. -Chia-Ming, O. -Lee, S.: J. Mater. Proc. Tech., 140, 2003, p. 588 .

[126] Stanford, N. -Barnett, M.R.: J. Alloys Comp., 466, 2008, p. 182.

[127] Chuvil'deev, V.N. -Nieh, T.G. -Gryazov, M.Y. -Sysoev, A.N. -Kopylov, V.I.: Scr. Mater., 50, 2004, p. 861.

[128] Panicker, R. -Chokshi, A.H. -Mishra, R.K. -Verma, R. -Krajewski, P.E.: Acta Mater., 57, 2009, p. 3683.

[129] Watanabe, H. -Mukai, T. -Ishikawa, K. -Okanda, Y. -Kohzu, M. -Higashi, K.: J. Jpn. Inst. Light Met., 49, 1999, p. 401.

[130] Chuvil'deev, V.N. -Kopylov, V.I. -Gryaznov, M.Y. -Sysoev, A.N.: Doklady Akademii Nauk., 391, 2003, p. 47.

[131] Tan, J.C. -Tan, M.J.: Mater. Sci. Eng. A, 339, 2003, p. 81.

[132] Takuda, H. -Kikuchi, S. -Hatta, N.: J. Mater. Sci., 27, 1992, 937.

[133] Mabuchi, M. -Ameyama, K. -Iwasaki, H. -Higashi, K.: Acta Mater., 47, 1999, p. 2047.

[134] Watanabe, H. -Mukai, T. -Ishikawa, K. -Higashi, K.: Scr. Mater., 46, 2002, p. 851. 


\section{FIGURES}

(a)

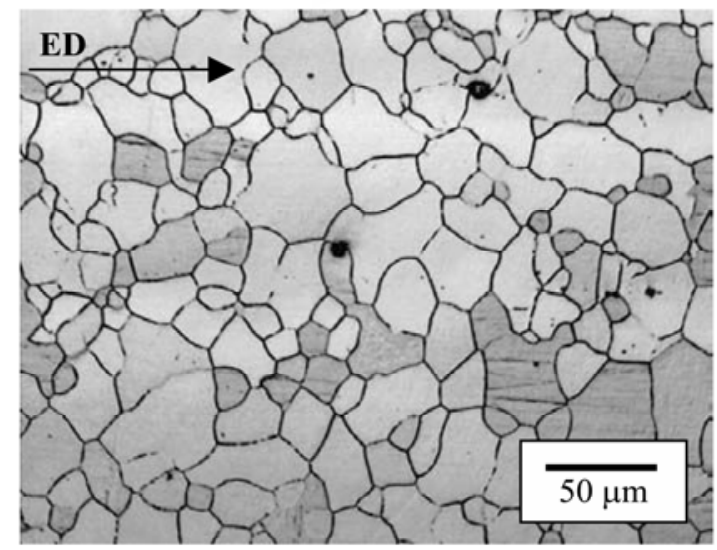

(b)

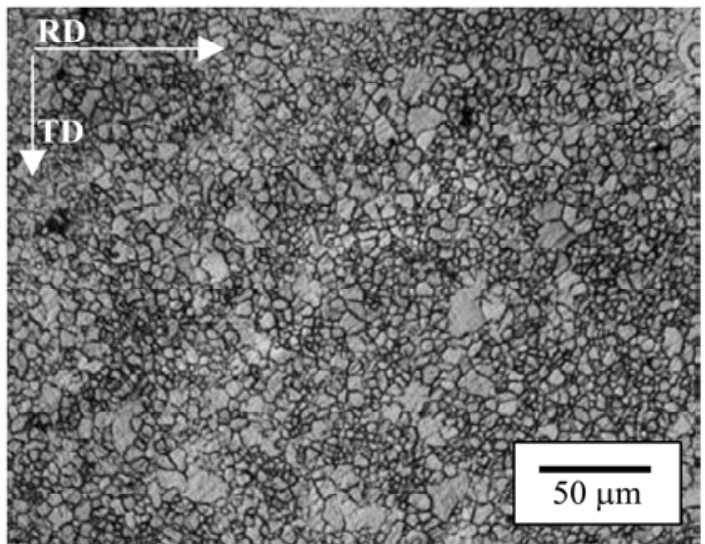

Figure 1. Optical micrographs showing the microstructure of the AZ61 alloy (a) in the asreceived condition and (b) after large strain hot rolling at $375{ }^{\circ} \mathrm{C}$ consisting on three passes with thickness reductions of $20 \%, 35 \%$, and $55 \%$, respectively. $\mathrm{ED}=$ extrusion direction of the asreceived material. $\mathrm{RD}=$ rolling direction. $\mathrm{TD}=$ transverse direction [15]. 
(a)

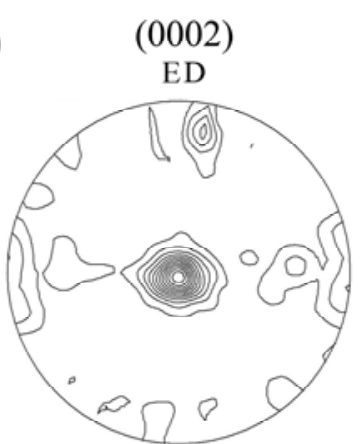

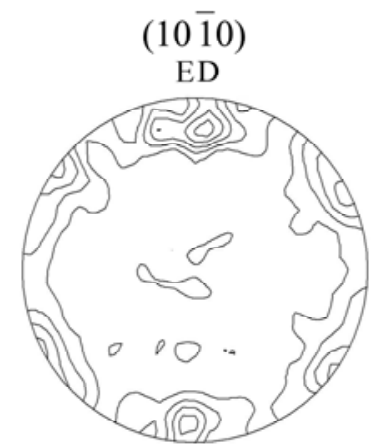

$(11 \overline{2} 0)$

ED

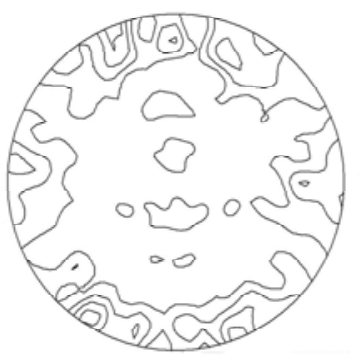

Intensity levels: $1,2,3,4,5,6,7,8,9,10,11,12,13,14$

(b)

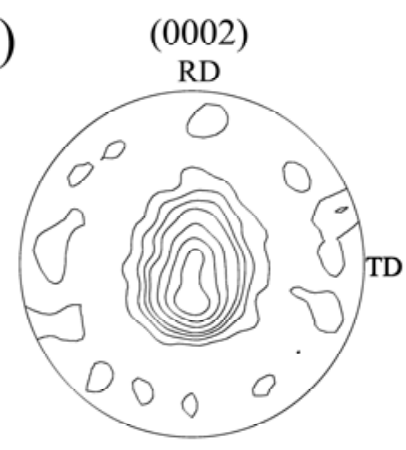

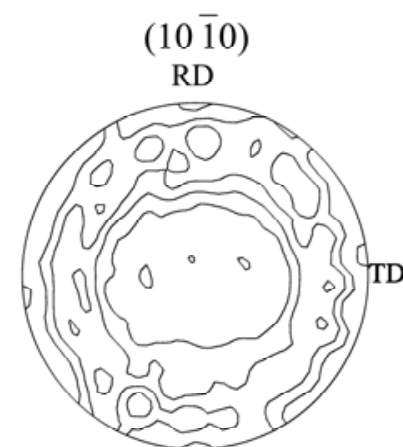

Intensity levels: $0.5,1,1.5,2,3,4,5$.

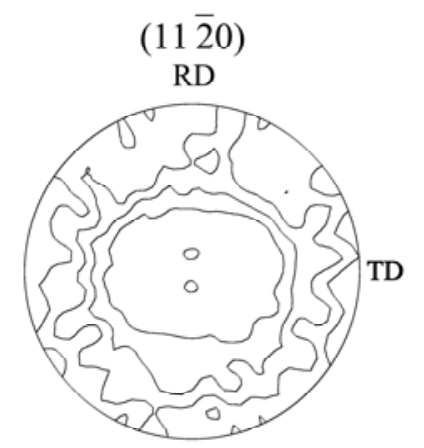

Figure 2: Comparison of the texture of the AZ61 alloy in the as-received condition (a) and after themomechanical processes of three rolling passes $20 \%+35 \%+55 \%$ (B) [15]

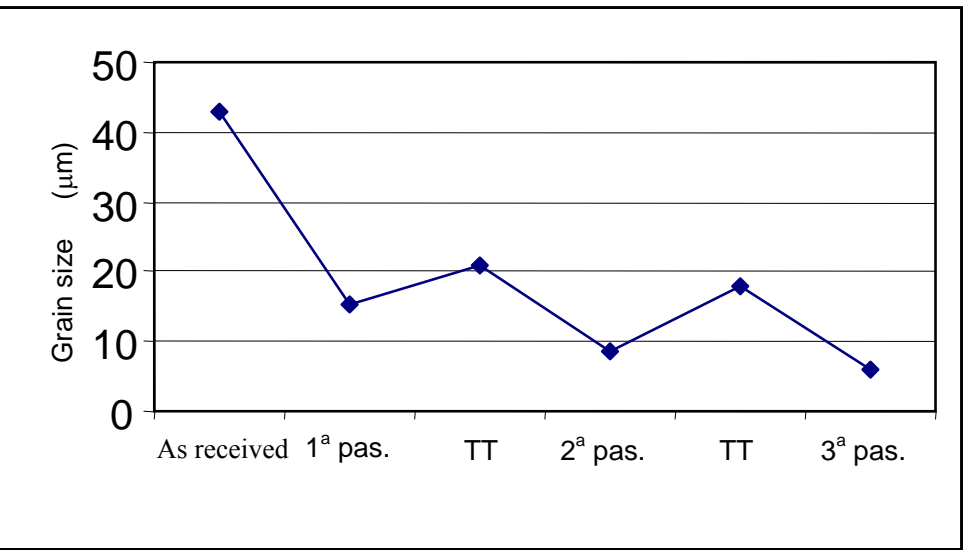

Figure 3: Grain size evolution during LSHR processing [15]

(a)

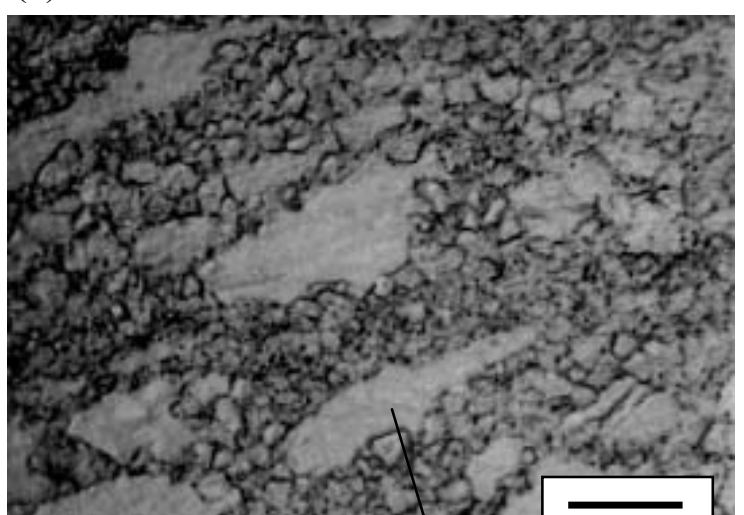

(b)

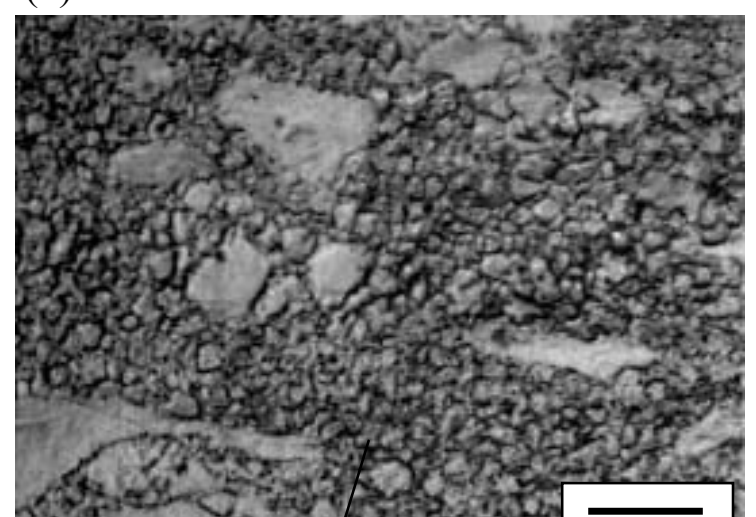


Figure 4 Distribution of shear bands with recrystallized grains across the AZ61 sample [15]

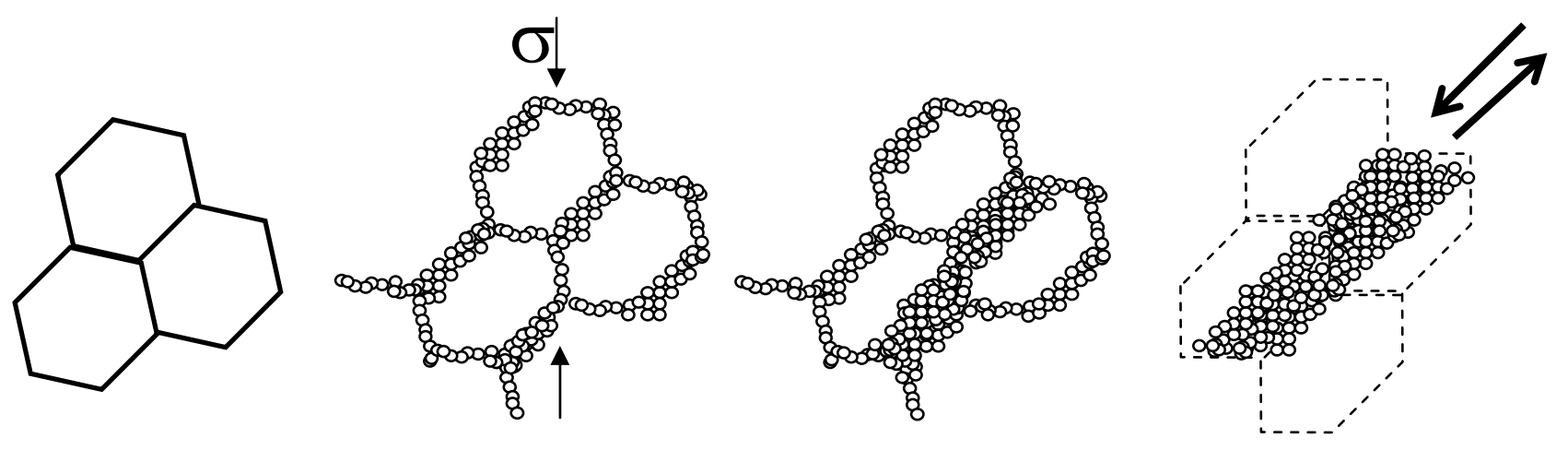

Figure 5 Schematic showing the model proposed by Ion et al. [46] adapted for the formation of ductile shear zones or bands of localized deformation during rolling [15]
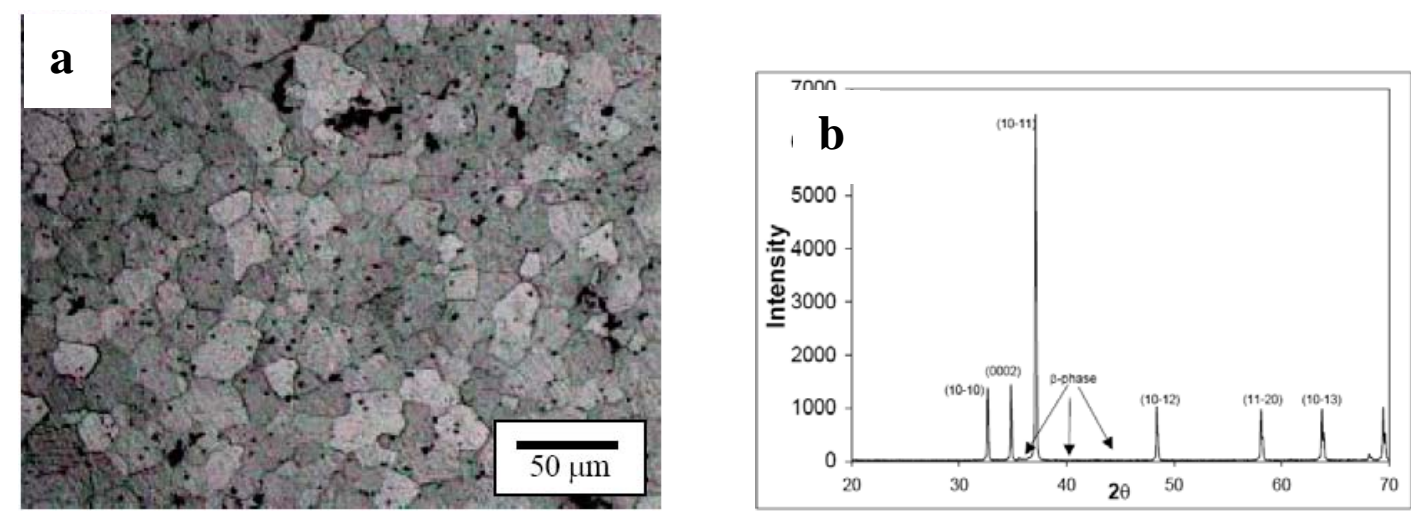

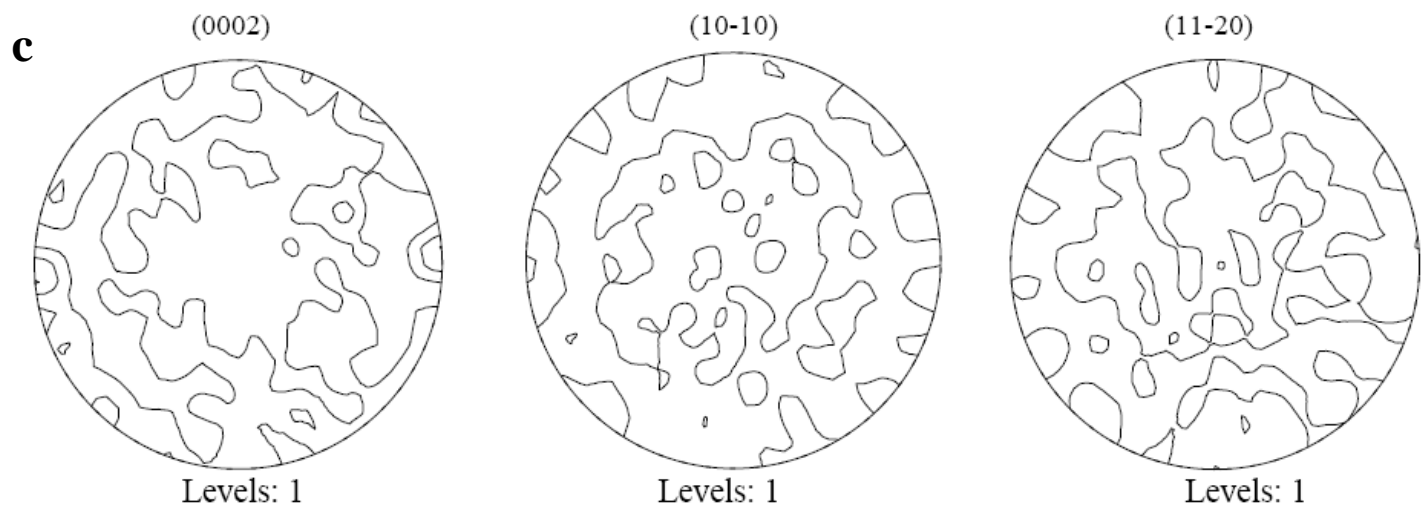

Figure 6(a) Optical micrograph showing the microstructure of the as-cast AZ91 solution treated at $698 \mathrm{~K}$ for $1 \mathrm{~h} \mathrm{(b)} \mathrm{X-ray} \mathrm{Debye} \mathrm{patterns} \mathrm{showing} \mathrm{the} \mathrm{peaks} \mathrm{corresponding} \mathrm{to} \mathrm{the} \mathrm{Mg}$ matrix (indexed peaks) and to the $\beta$-phase (c) X-ray (0002), (10-10) and (11-20) direct pole figures showing the macrotexture [32]. 

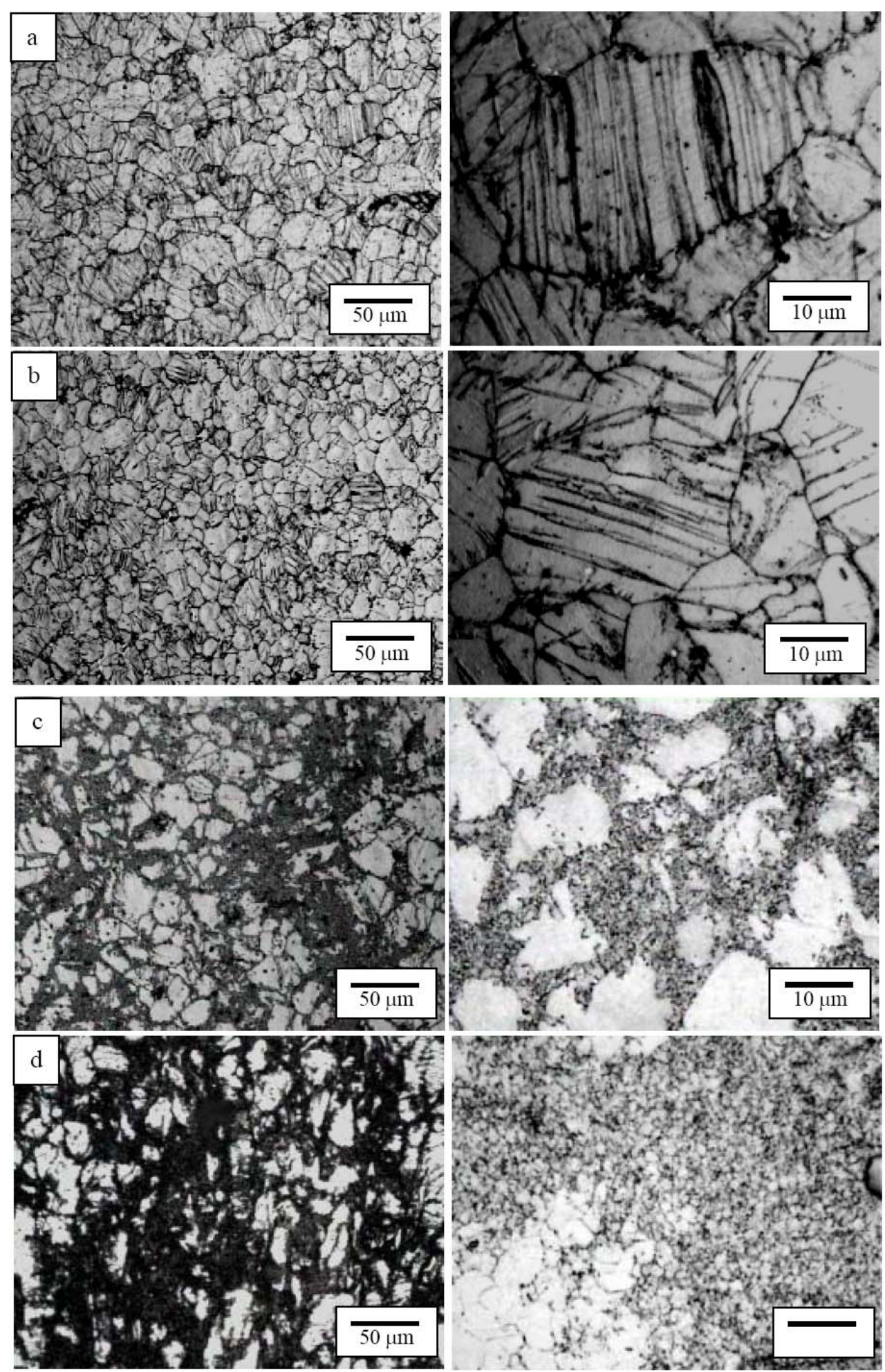

Figure 7. Evolution of the microstructure of the AZ91 alloy after one pass rolling at $673 \mathrm{~K}$ with different thickness reductions. (a) $30 \%$, (b) $50 \%$, (c) $71 \%$ and (d) $83 \%$. [32] 
(a) $\quad 30 \%$

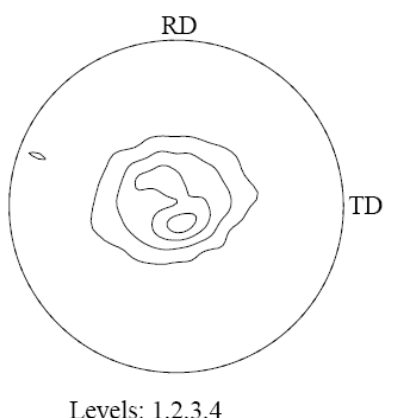

(c) $71 \%$

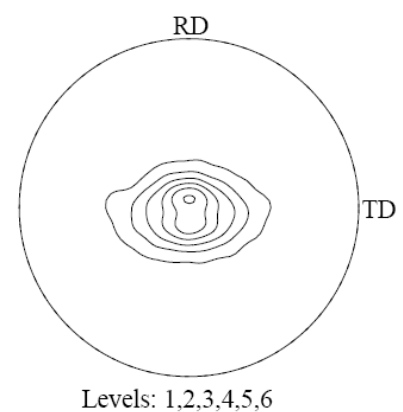

(b) $50 \%$

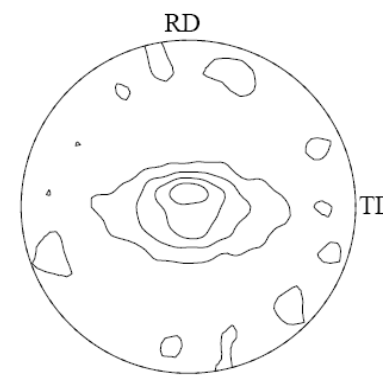

Levels: $1.2,3,4$

(d) $\quad 83 \%$

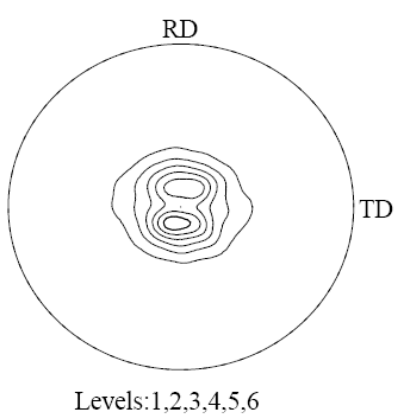

Figure 8. X-ray (0002) direct pole figures showing the texture evolution of the AZ91 alloy after one pass rolling at $673 \mathrm{k}$ with different thickness reductions. (a) $30 \%$, (b) $50 \%$, (c) $71 \%$ and (d) $83 \%$ [32]
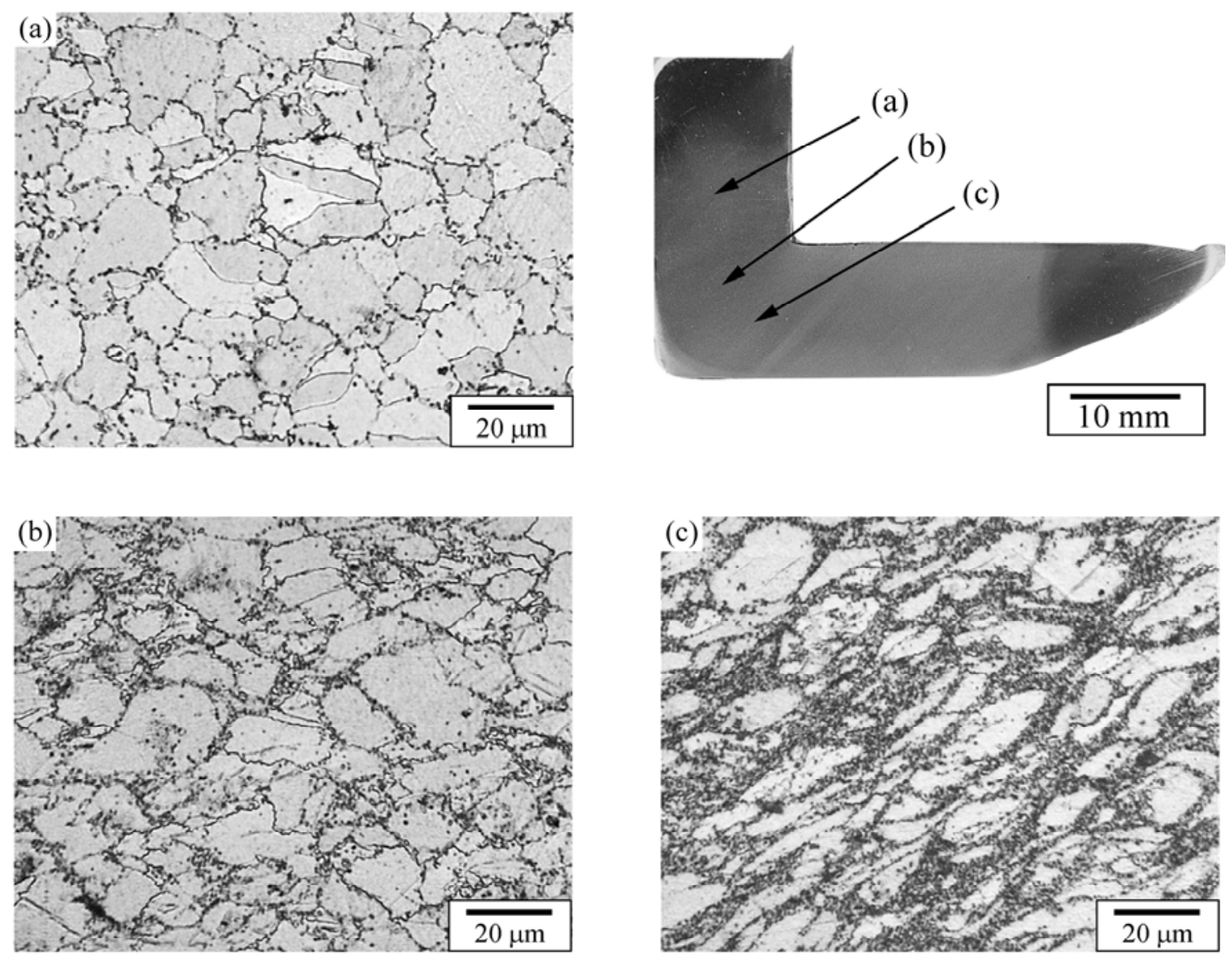

Figure 9. Microstructural evolution during ECAP of the AM60 alloy 

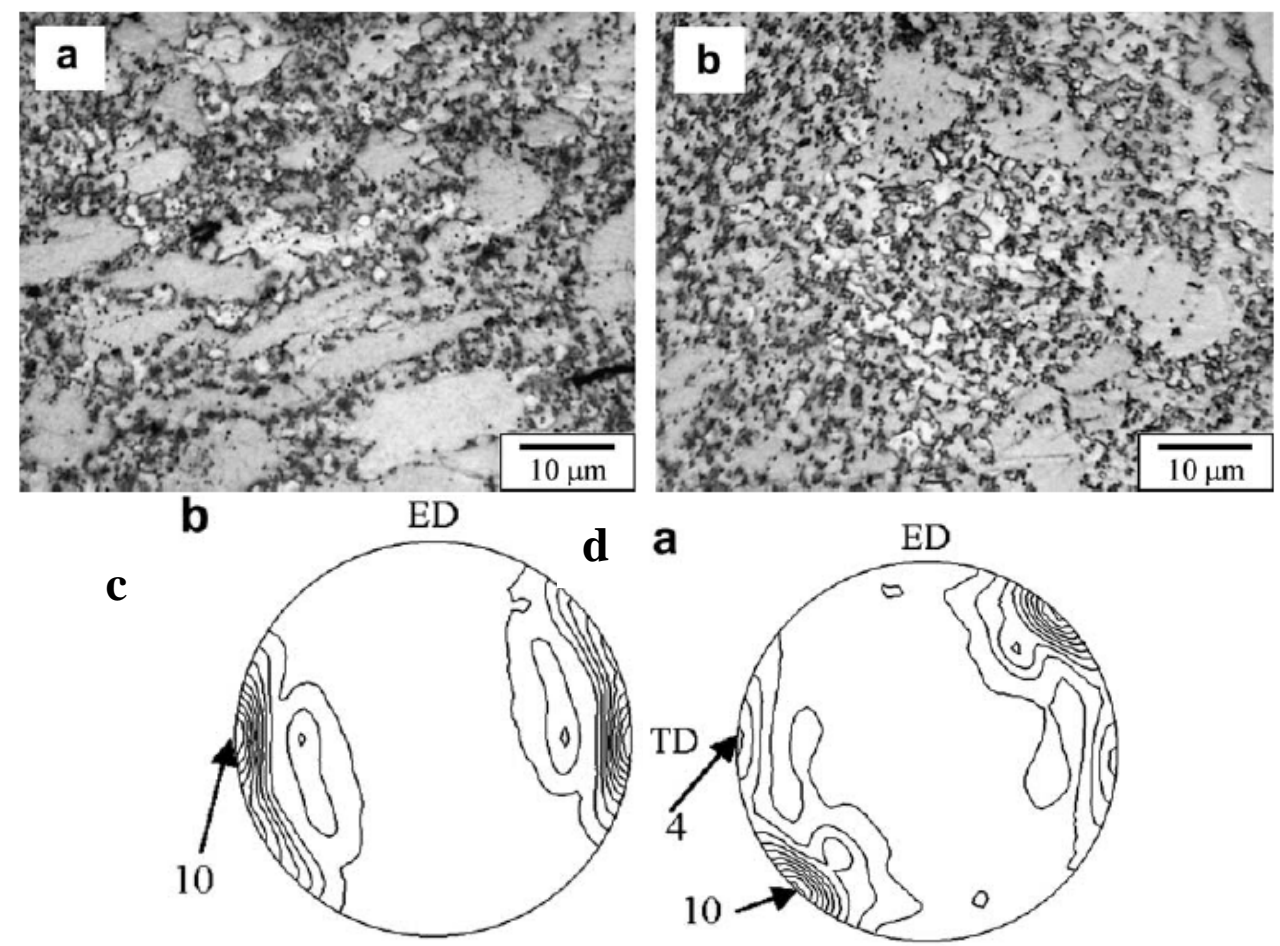

Figure 10. Microstructure and texture of two pass ECAPed AM60 alloy (a) and (c) for route A and (b) and (d) for route $\mathrm{C}$ respectively [21]
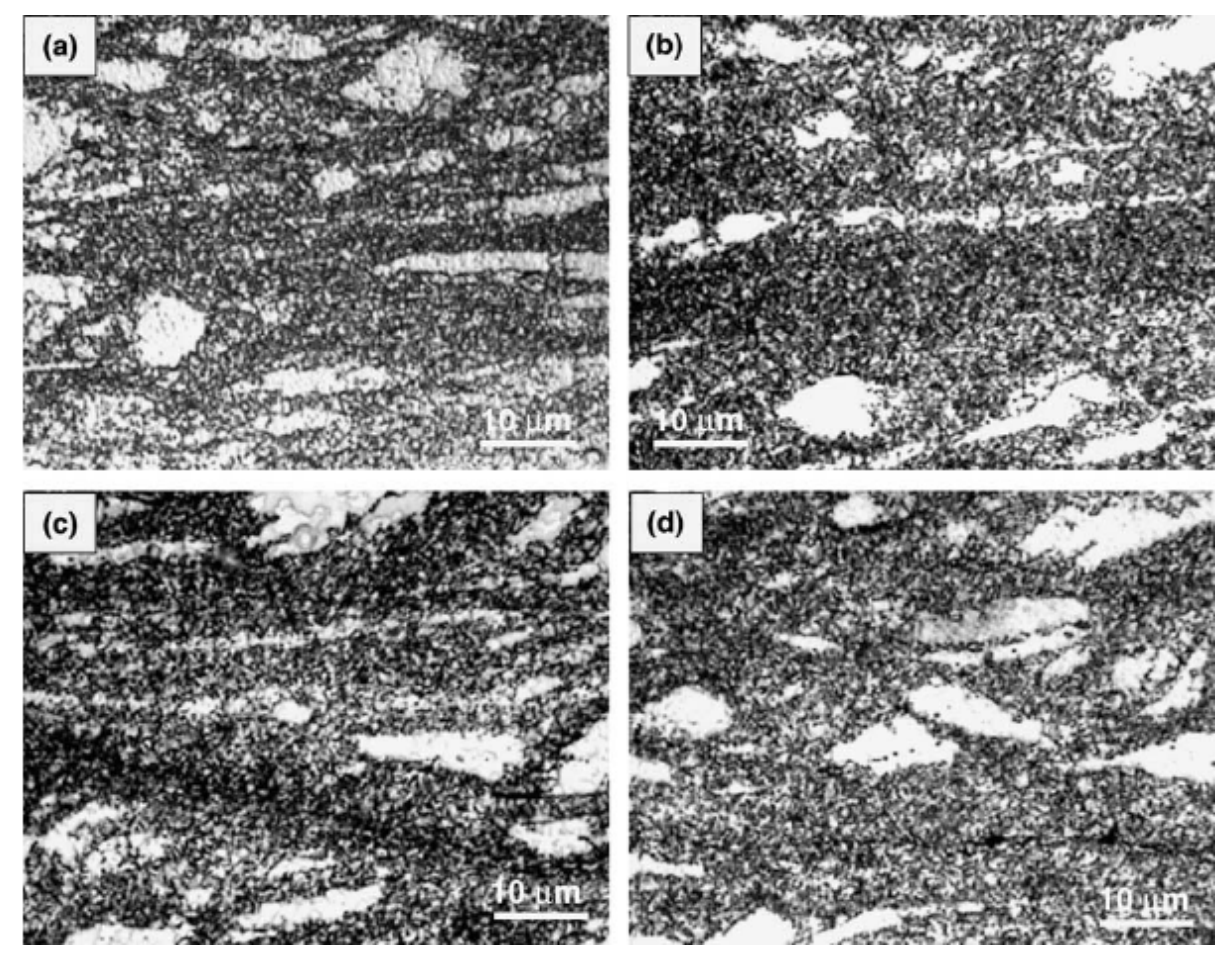

Figure 11. Microstructure of the AZ91 alloy processed by accumulative roll bonding (a) After one pass, (b) two passes, (c) three passes and (d) four passes [85] 


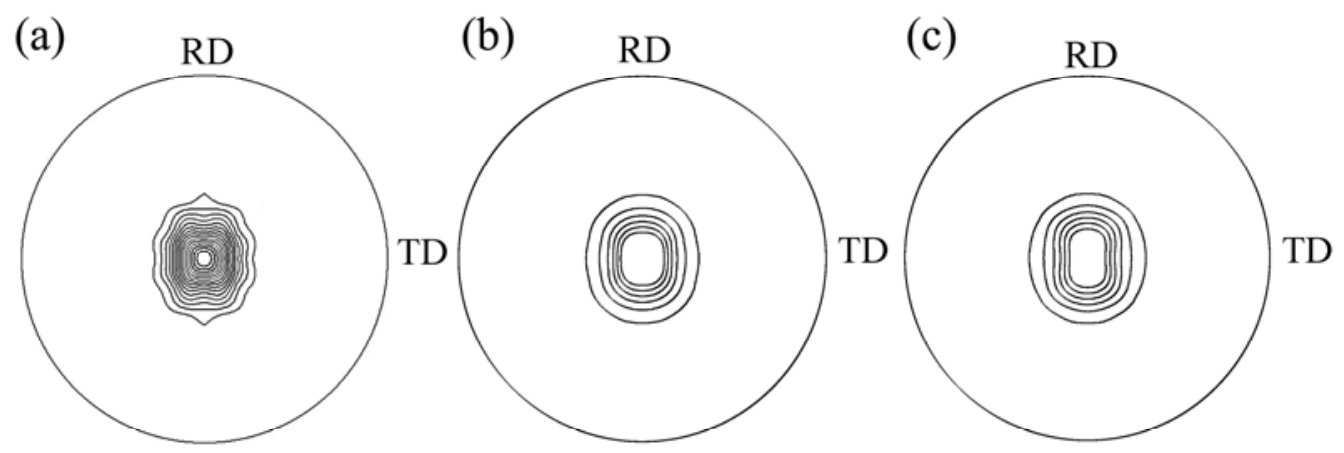

Levels: $1,2,3,4,5 \ldots 16$.

Figure 12. Texture of (a) AZ31 before ARB (b) AZ31 after ARB 4passes (c) AZ91 after ARB 4 passes, (0002) direct pole figures. [85]

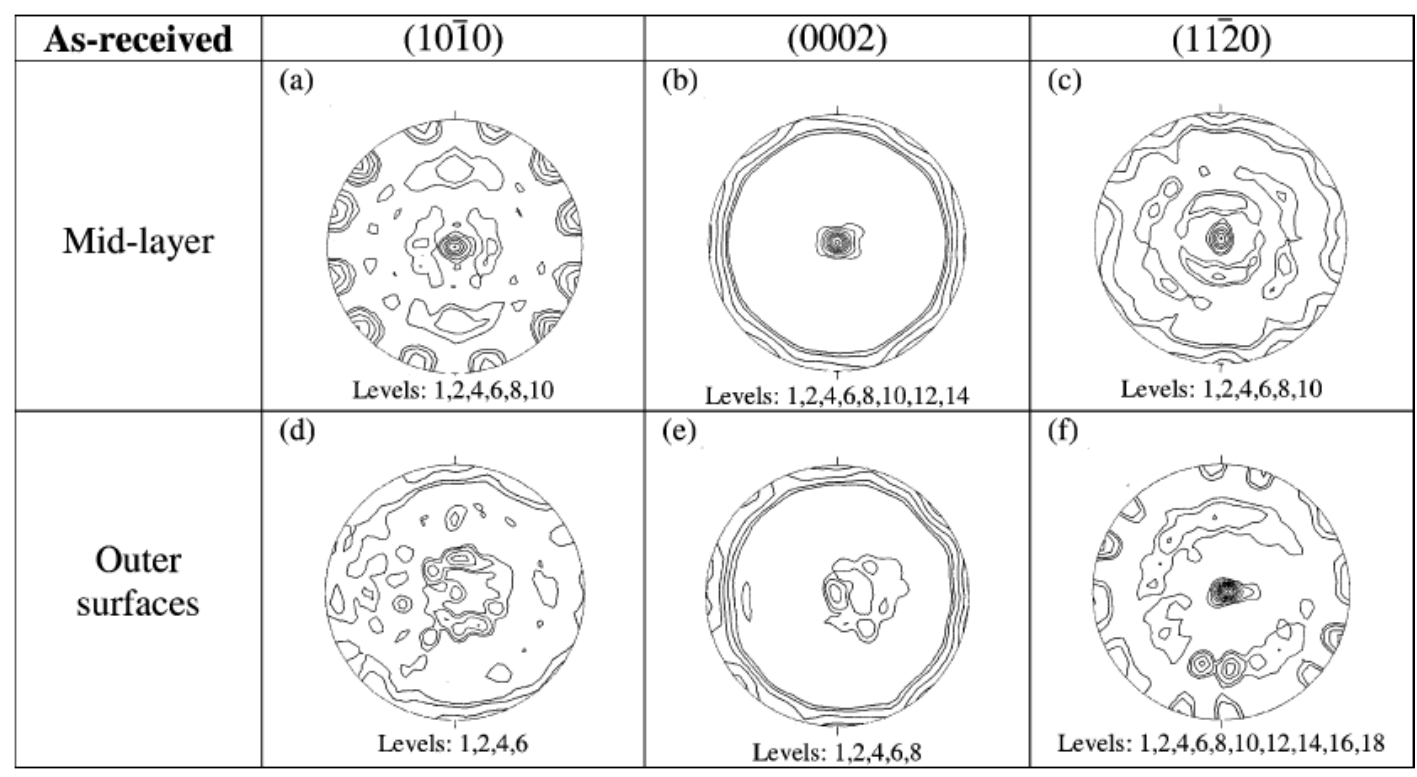

Figure 13. Direct pole figures showing the textures of the as-extruded AZ31 alloy [89] 


\begin{tabular}{|c|c|c|c|}
\hline $520^{\circ} \mathrm{C}-3 \mathrm{~h}$ & $(10 \overline{1} 0)$ & $(0002)$ & $(11 \overline{2} 0)$ \\
\hline Mid-layer & (a) & (b) & (c) \\
\hline $\begin{array}{c}\text { Outer } \\
\text { surfaces }\end{array}$ & $\infty$ & (e) & Levels:1,2,4,6,8,10,12,14 \\
\hline
\end{tabular}

Figure 14. Direct pole figures showing the texture of the AZ31 alloy annealed at 793K for $3 \mathrm{~h}$. The vertical axis is parallel to the extrusion direction and the horizontal axis is parallel to the transverse direction [89]

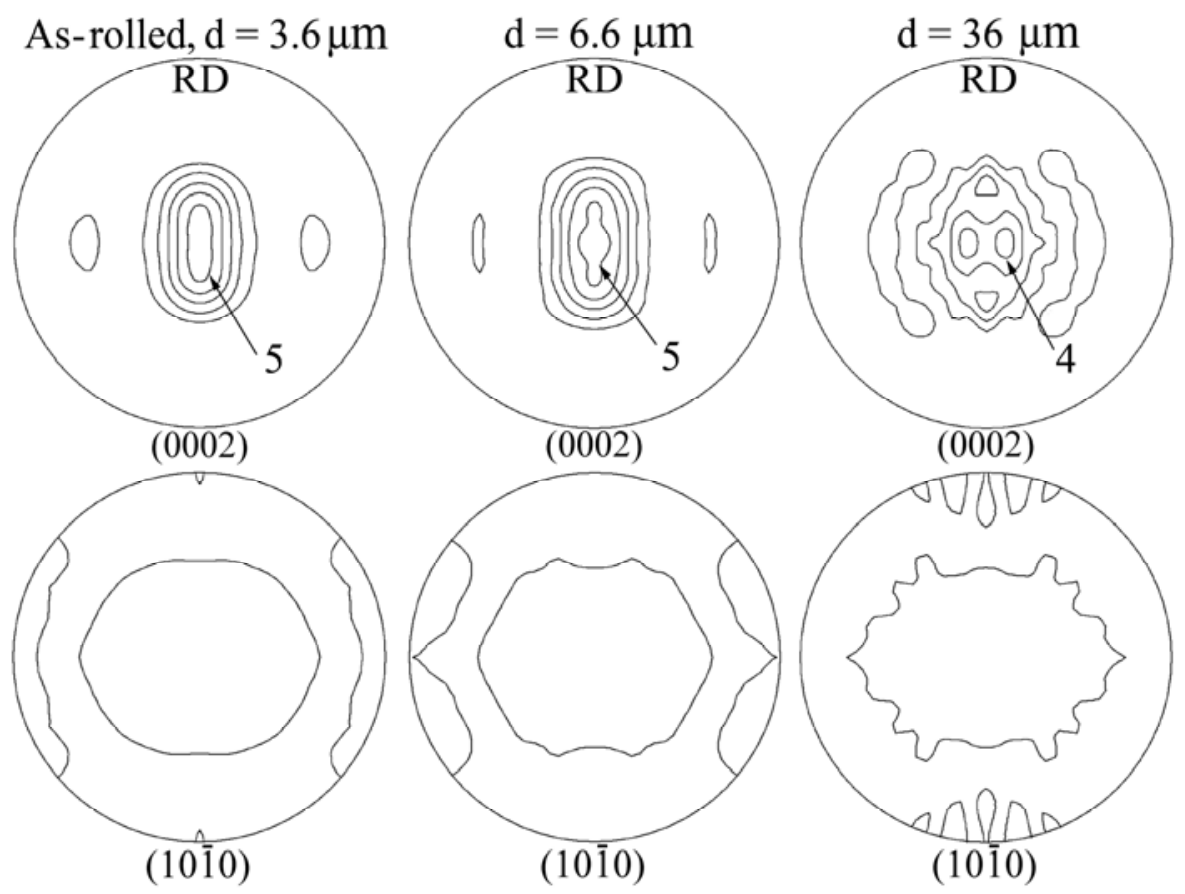

Figure 15: Texture of the AZ61 alloy processed in the following ways: (a) 2 rolling passes at $400^{\circ} \mathrm{C}$, (b) 2 rolling passes at $400^{\circ} \mathrm{C}$ plus 100 minutes at $300{ }^{\circ} \mathrm{C}(\mathrm{d}=6.6 \mu \mathrm{m})$ and (c) 2 rolling passes at $400^{\circ} \mathrm{C}$ plus 1000 minutes at $400{ }^{\circ} \mathrm{C}(\mathrm{d}=36 \mu \mathrm{m})$ [24]. 


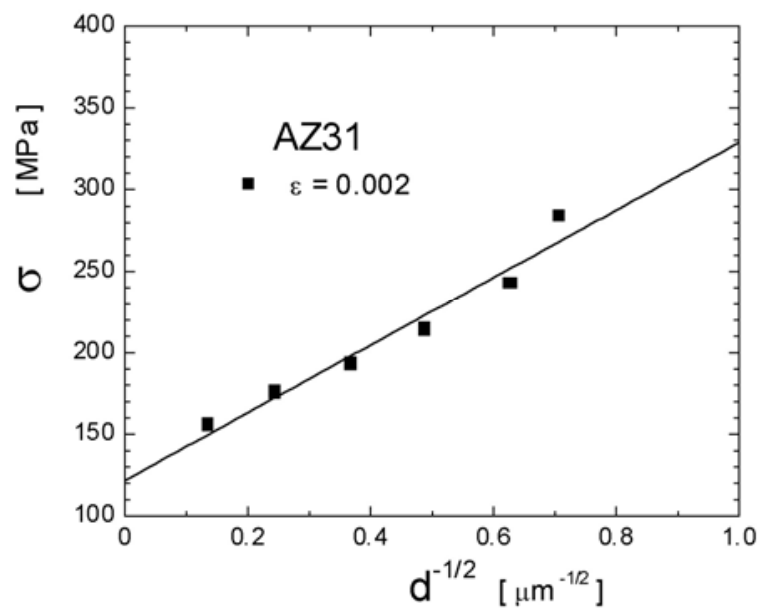

Figure 16: Yield stress as a function of $\mathrm{d}^{-1 / 2}$ for the AZ31 alloy with a basal texture. [21]

\section{冈}

Figure 17 Effect of the grain size on the rolled AZ31 alloy (a) Stress-strain curves [21] (b) work hardening rate [21](c) strain rate sensitivity [23]. 

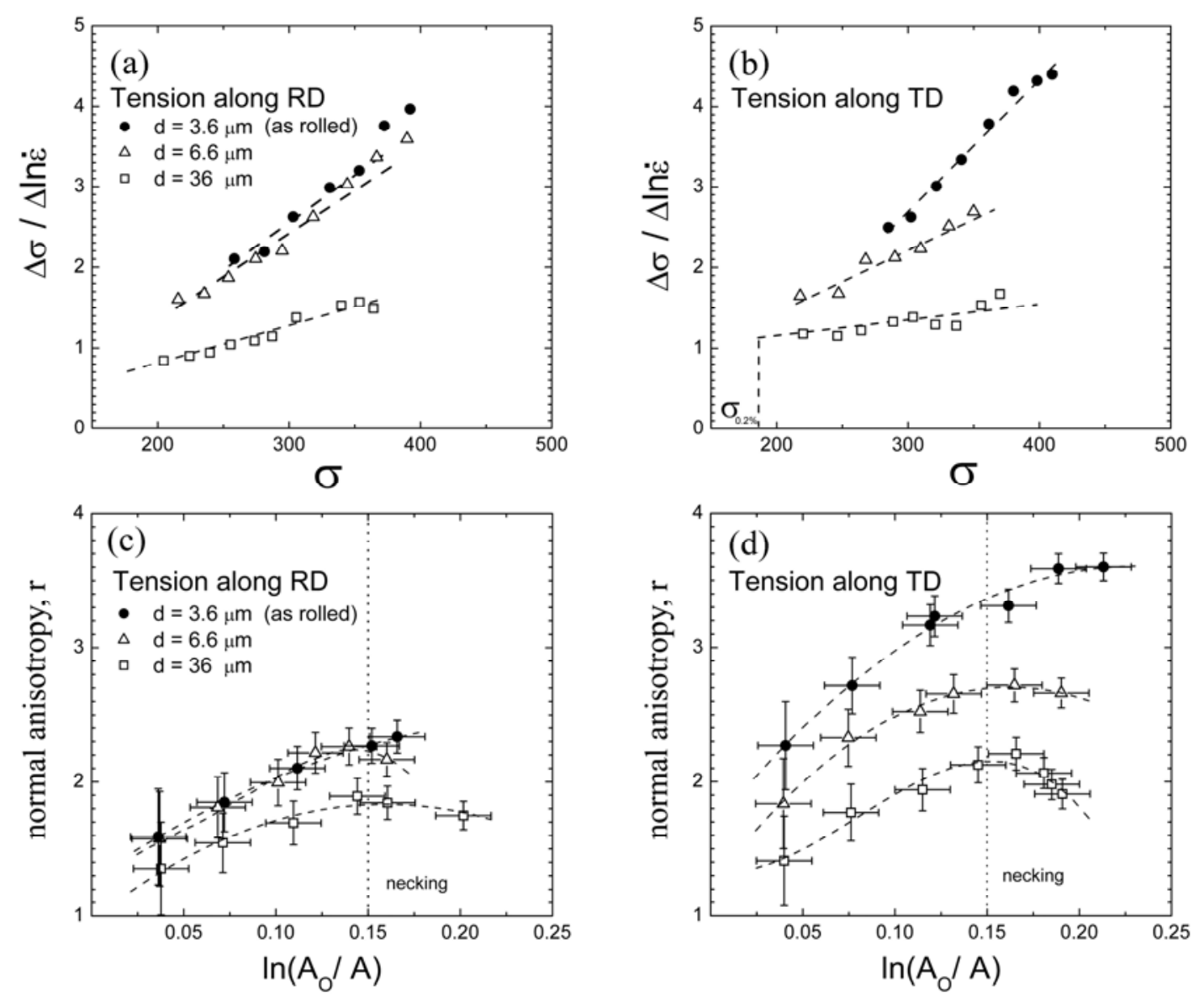

Figure 18. Effect of the grain size on the rolled AZ61 alloy: Evolution of the strain rate sensitivity as a function of stress for RD (a) and TD (b) samples respectively. Evolution of the normal anisotropy as a function of the plastic strain for RD (c) and TD (d) samples respectively. [24]
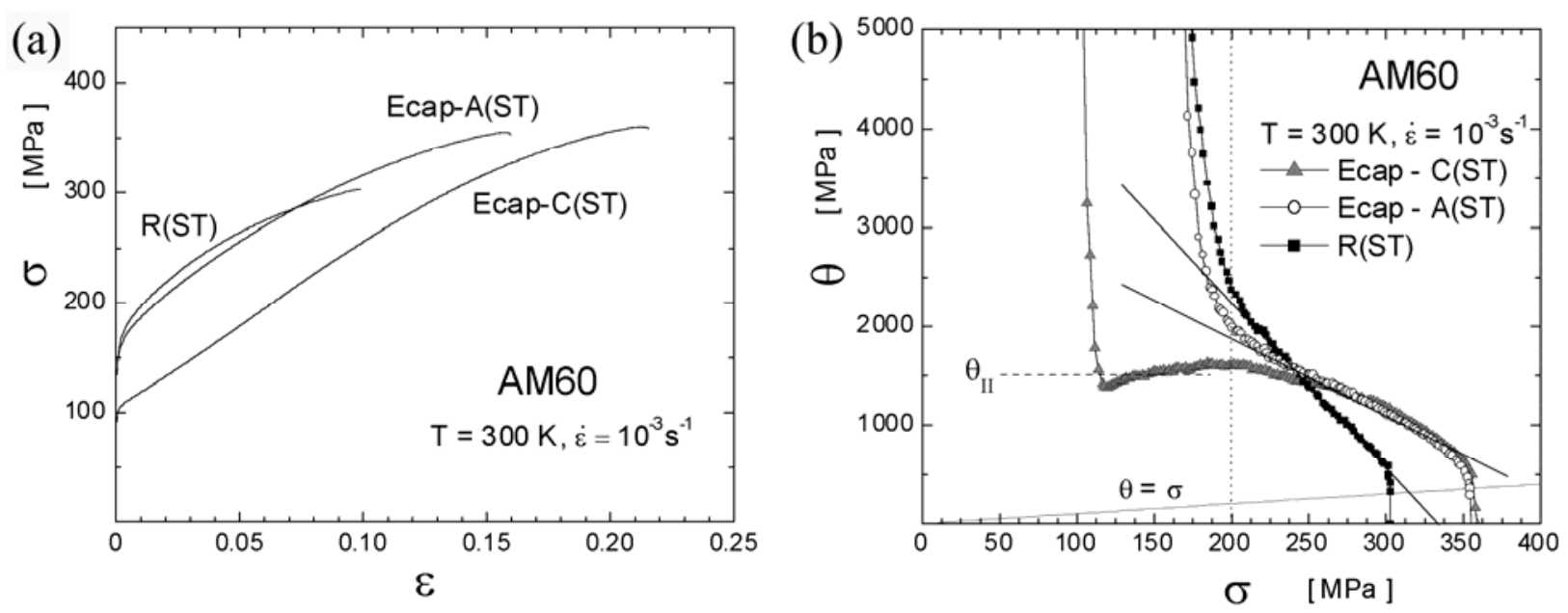

Figure 19. AM60 alloy: (a) stress-strain curves of samples ECAP-A+ST, ECAP-C+ST and LSHR+ST, (b) corresponding curves of macroscopic WH rate vs flow stress [21] 

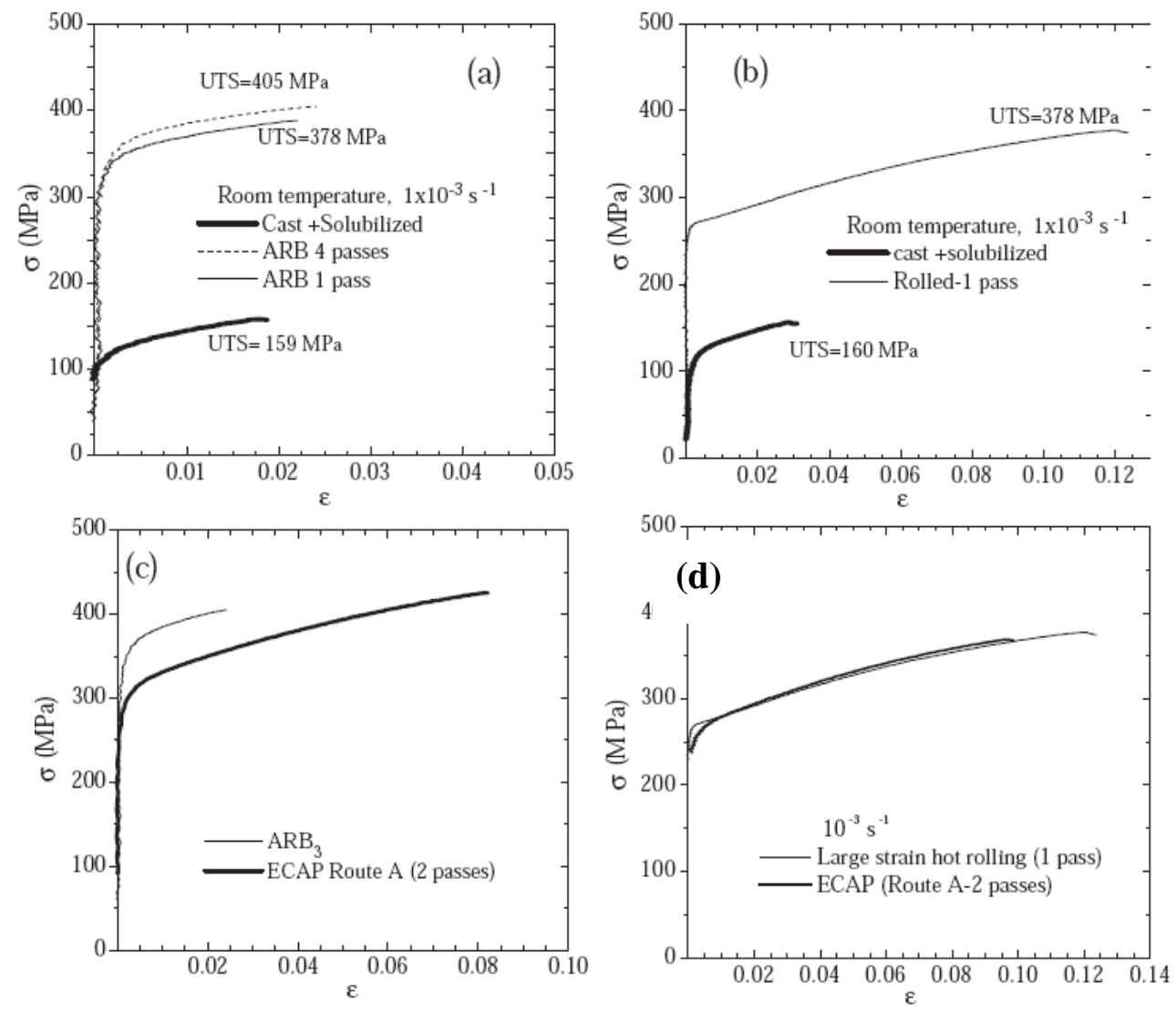

Figure 20. Mechanical properties at room temperature: (a) and (b) comparison between the solution heat treated and the rolled materials for AZ91 and AM60 alloys, (c) comparison of ECAP sample with ARB 3pass sample of AZ91 alloy and (d) comparison of ECAP sample with LSHR sample of AM60 alloy [67]

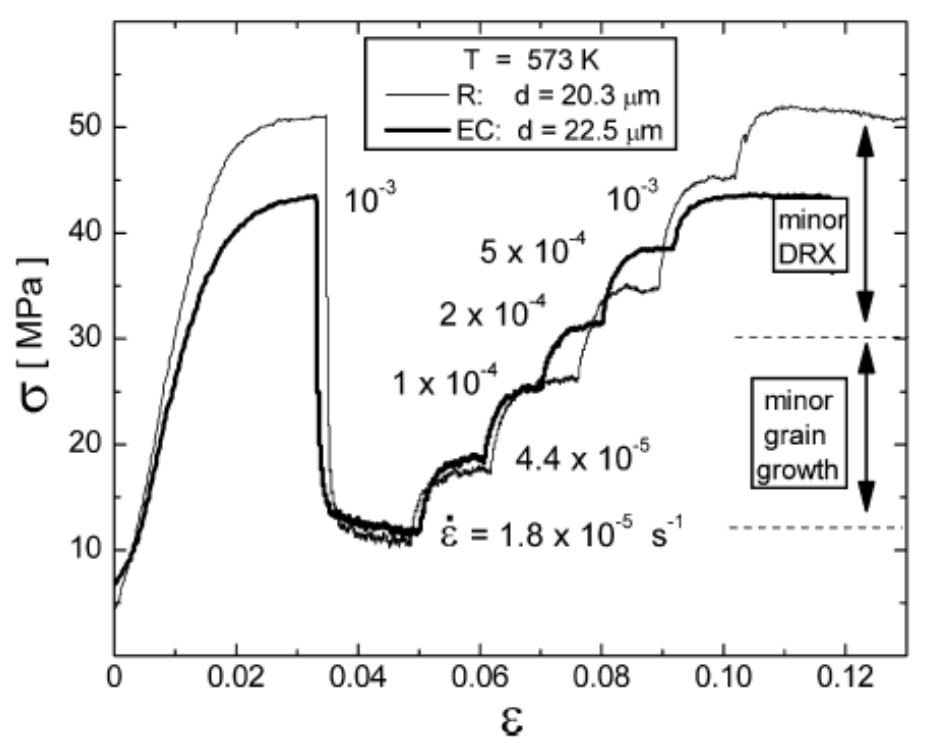

Figure 21. Strain-rate change test of two samples: an R sample with a grain size of $d=20.3 \mu \mathrm{m}$ and an EC sample with $\mathrm{d}=22.5 \mu \mathrm{m}$. Zones with minor grain growth and minor dynamic recrystallization are indicated.[16] 

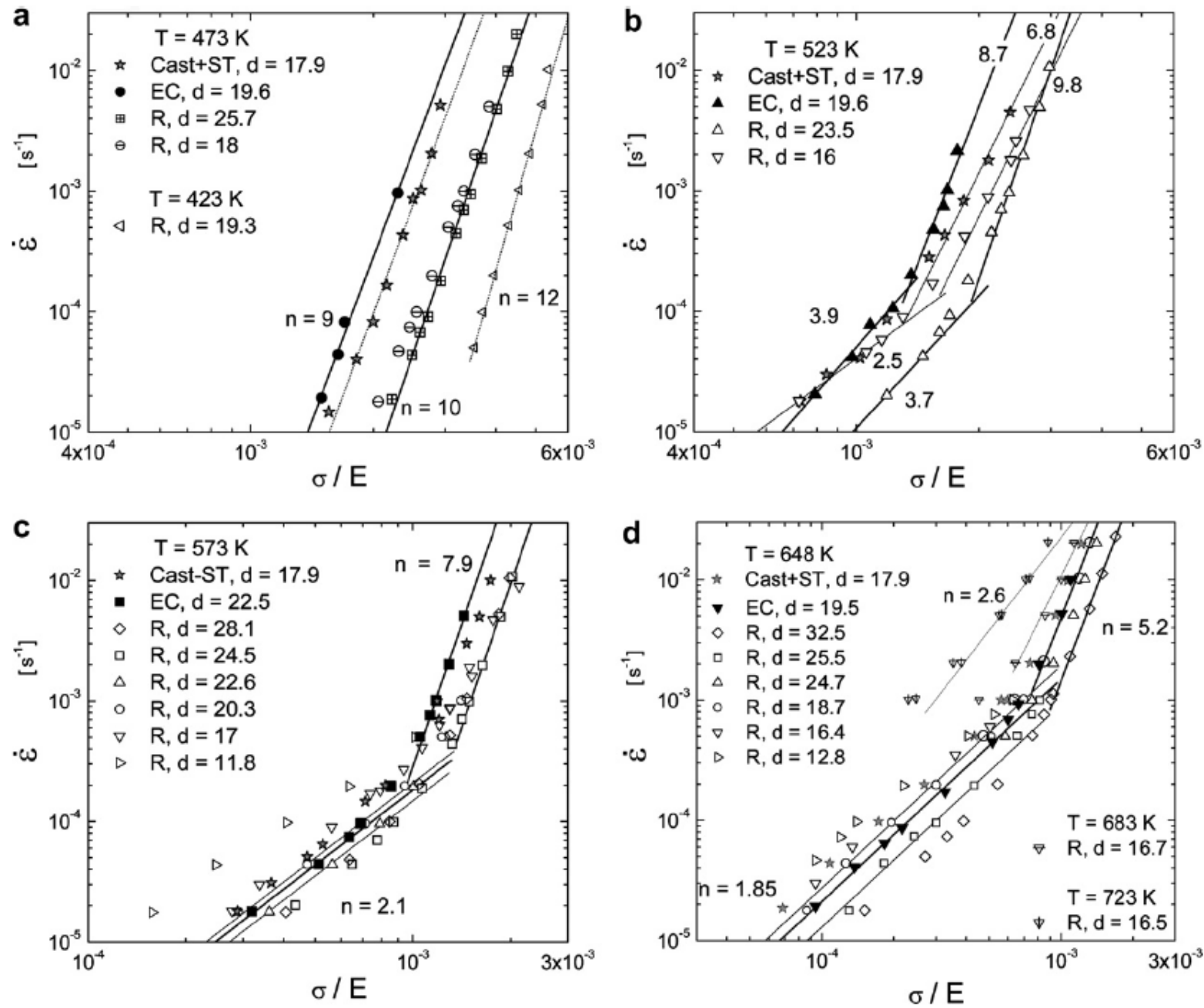

Figure 22. The strain rate against the stress of the AM60 alloy samples: Cast + Solution treated (ST), R and EC samples with different grain sizes tested at various temperatures. Grain sizes are given in microns. [16]
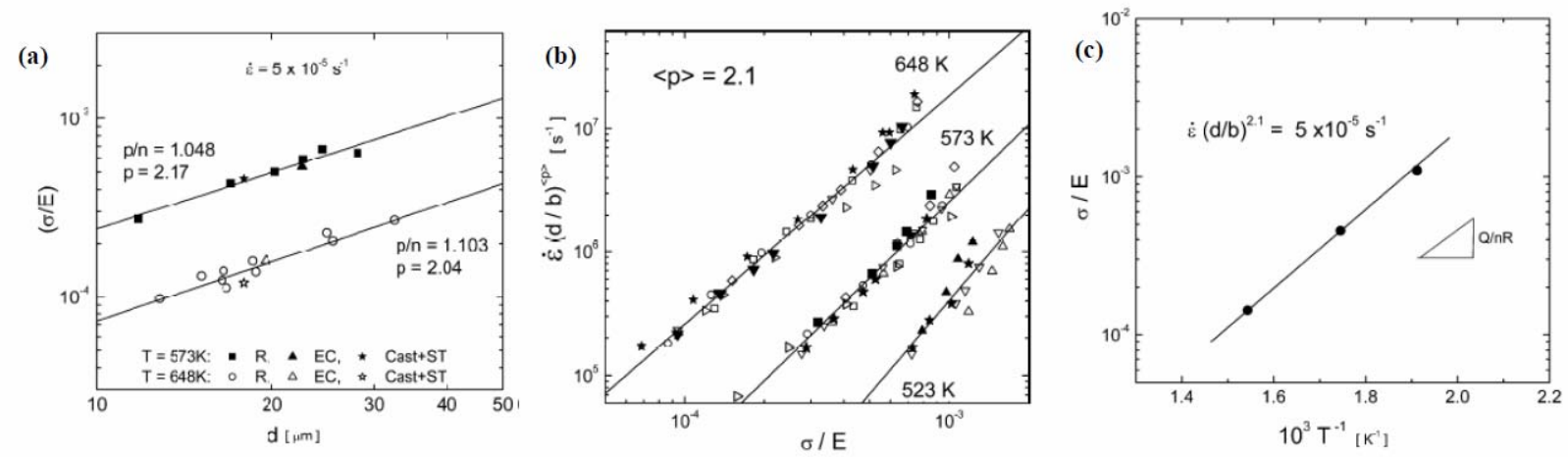

Figure 23. For samples of different textures, (a) The stress at 573 and $648 \mathrm{~K}$, measured at a strain rate of $5 \times 10^{-5} \mathrm{~s}^{-1}$, is plotted as a function of the grain size. (b) Compensated strain rate, $\dot{\varepsilon}(\mathrm{b} / \mathrm{d})^{2.1}$ as a function of stress. (c) The stress is plotted against $\mathrm{T}^{-1}$ in a semilogarithmic representation at a given strain rate for determination of the activation energy [16] 
(a)

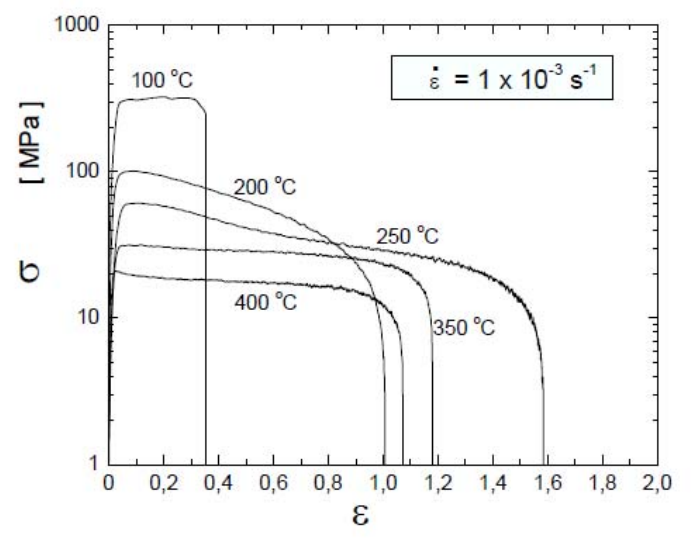

(b)

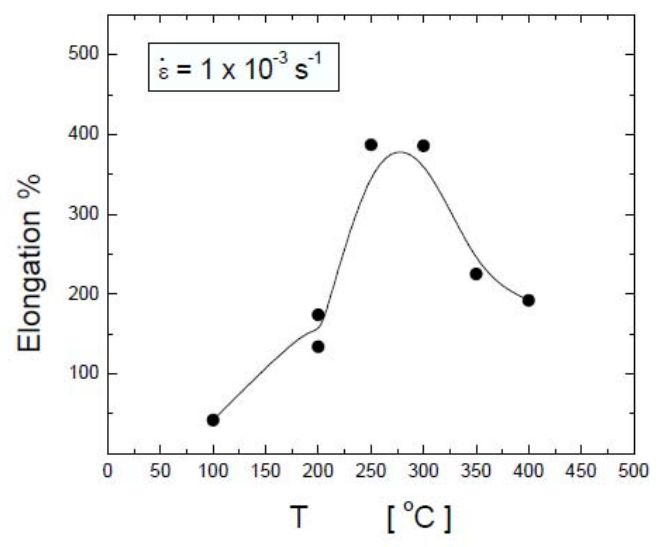

(c)

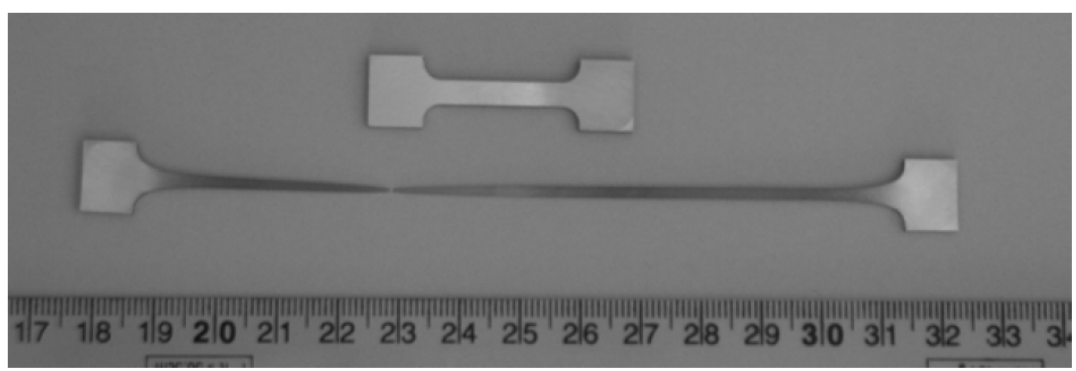

Figure 24. (a) Stress vs. strain curves corresponding to the AZ61 alloy (processed via large strain hot rolling) deformed uniaxially in tension at $10^{-3} \mathrm{~s}^{-1}$ and at temperatures ranging from $373 \mathrm{~K}$ to $673 \mathrm{~K}$. The tensile axis is the rolling direction. (b) Elongations to failure achieved in the tests of Fig. 24a. (c) AZ61 tensile specimen tested at $523 \mathrm{~K}$ and $10^{-4} \mathrm{~s}^{-1}$.[69]

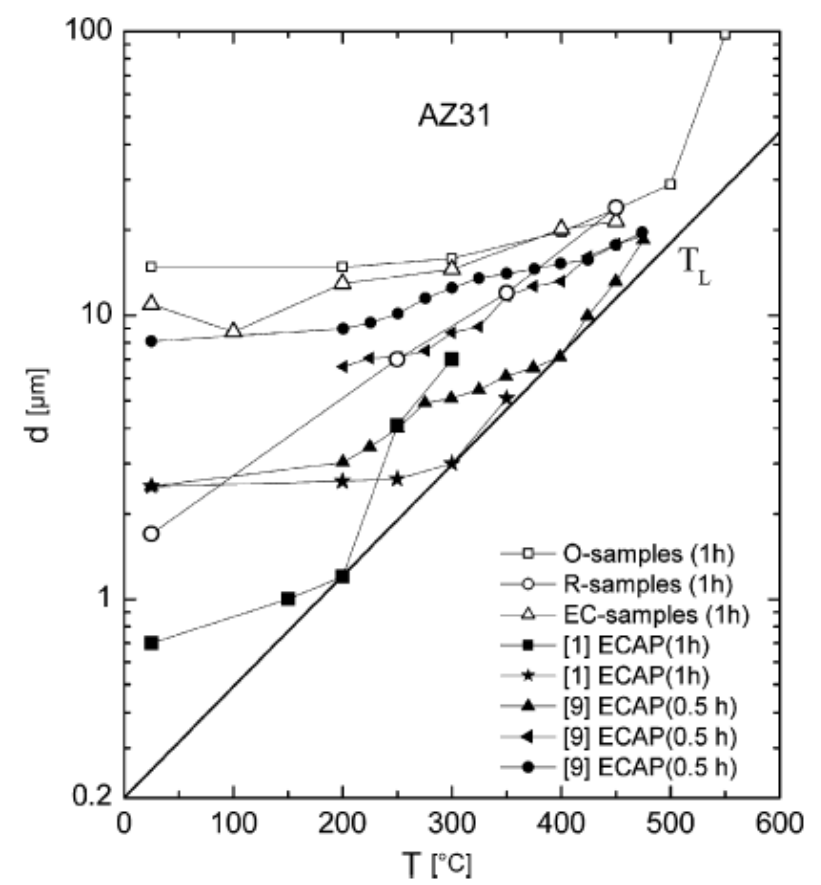

Figure 25. The variation of grain size as a function of temperature, for the AZ31 alloy, during annealing treatments for data obtained in this work in comparison with data from the literature [110]. 
(a)

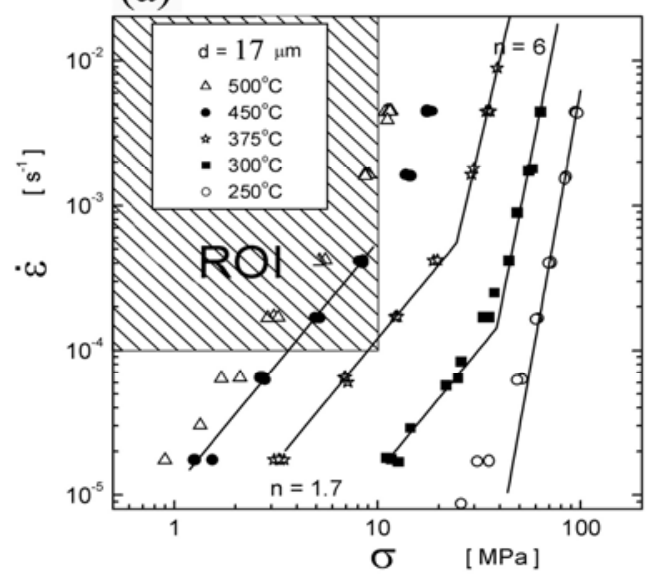

(c)

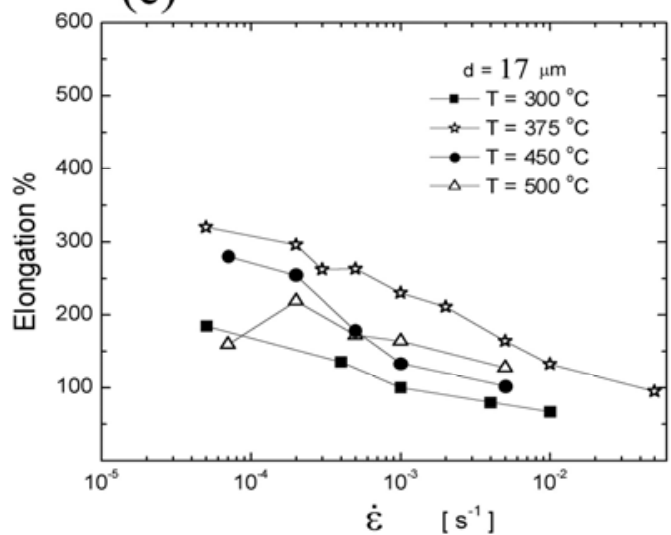

(b)

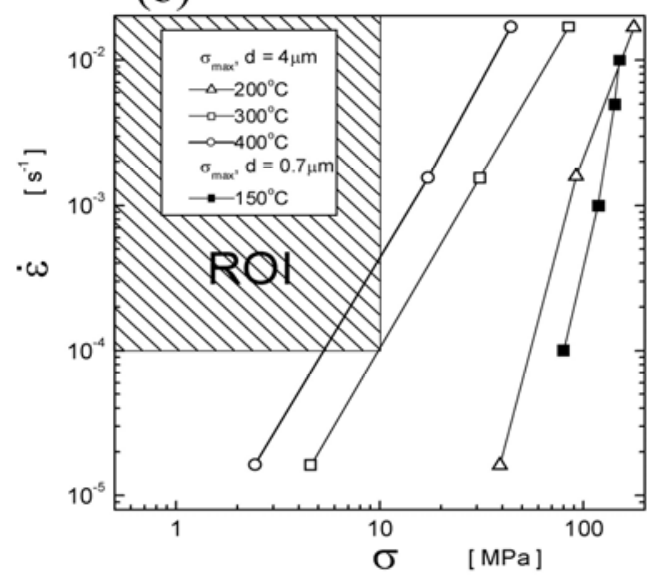

(d)

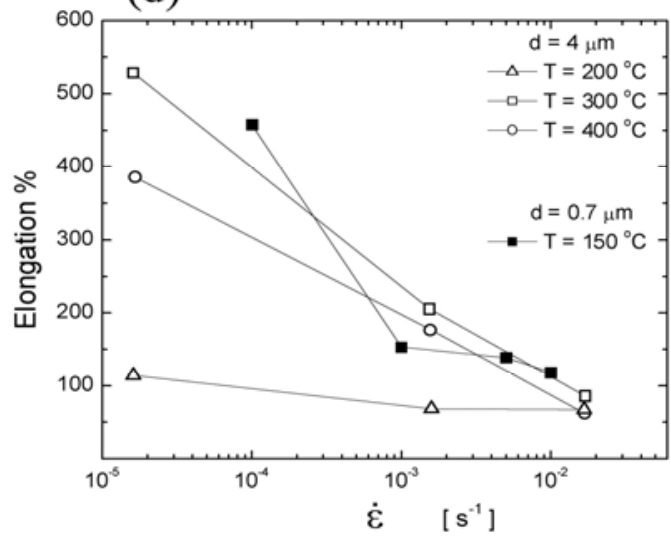

Figure 26. True strain rate vs. True stress curves for the AZ31 alloy: (a) AZ31-O, d=17 $\mu \mathrm{m}$. (b) AZ31 with $d=4 \mu \mathrm{m}$. The region of interest, ROI, for superplastic forming is depicted. Elongations to failure as a function of the strain rate (c) and (d). [110] 
TABLES

\begin{tabular}{|c|c|c|c|c|}
\hline Alloy & $\begin{array}{c}\text { Initial } \\
\text { condition }\end{array}$ & $\begin{array}{l}\text { Thickness } \\
\text { reduction }\end{array}$ & Grain size & Reference \\
\hline AZ61 & Extruded & $20 \%+70 \%$ & $2 \mu \mathrm{m}$ & 15 \\
\hline AZ91 & Casting & $83 \%$ & $1.4 \mu \mathrm{m}$ & 32 \\
\hline AM60 & Casting & $80 \%$ & $1 \mu \mathrm{m}$ & 52 \\
\hline AZ31 & Rolled & $10 \%+70 \%$ & $2-3 \mu \mathrm{m}$ & 67 \\
\hline
\end{tabular}

Table 1. Dynamically recrystallized grain sizes obtained by large strain hot rolling in different alloys

\begin{tabular}{|l|l|l|l|l|l|l|}
\hline Alloy & Method & $\begin{array}{l}\text { Grain } \\
\text { size }(\mu \mathrm{m})\end{array}$ & $\begin{array}{l}\text { Yield } \\
\text { strength } \\
(\mathrm{MPa})\end{array}$ & $\begin{array}{l}\text { Ultimate } \\
\text { strength } \\
(\mathrm{MPa})\end{array}$ & $\begin{array}{l}\text { Ductility } \\
(\%)\end{array}$ & Reference \\
\hline AM60 & Rolling & 1 & - & 378 & 12 & 66 \\
\hline AZ91 & ARB & 0.5 & & 405 & 2 & 66 \\
\hline AM50 & Rolling & 2.6 & 210 & 270 & 23 & 70 \\
\hline AM50 & Rolling & 1.2 & 236 & 306 & 15 & 70 \\
\hline AZ31 & ECAP & 1.7 & 118 & 244 & 26 & 98 \\
\hline AZ31 & ECAP & 1.8 & 138 & 268 & 31 & 98 \\
\hline AZ31 & ECAP & 1.9 & 221 & 315 & 29 & 98 \\
\hline AZ31 & ECAP & 0.37 & 372 & 445 & 9.7 & 98 \\
\hline AZ31 & ECAP & 5 & 113 & 255 & 35 & 100 \\
\hline AZ31 & ECAP & 2 & 136 & 275 & 32 & 100 \\
\hline AZ31 & $\begin{array}{l}\text { ECAP(two } \\
\text { stage })\end{array}$ & 0.5 & 231 & 300 & 29 & 100 \\
\hline AZ31 & ECAP & 15 & - & 270 & 50 & 34 \\
\hline AZ31 & ECAP & 19 & - & 250 & 45 & 101 \\
\hline AZ61 & ECAP & 15 & - & 302 & 34 & 73 \\
\hline AZ61 & ECAP & 12 & - & 317 & 39 & 73 \\
\hline AZ61 & ECAP & 11 & - & 329 & 35 & 73 \\
\hline AZ61 & ECAP & 10 & - & 317 & 42 & 73 \\
\hline AZ61 & ECAP & 8 & - & 310 & 55 & 73 \\
\hline AZ61 & ECAP & 0.5 & 351 & - & 30 & 78 \\
\hline AZ91 & Extrusion & - & 244 & 341 & 13 & 17 \\
\hline AZ91 & $\begin{array}{l}\text { Rapid } \\
\text { solidi }\end{array}$ & 0.35 & - & 400 & - & 106 \\
\hline fication & & & & & \\
\hline & & & & & & \\
\hline
\end{tabular}

Table 2. Comparison of the room temperature properties of several Mg-Al alloys processed using different technologies 